(1) Academy of Management Journal

2012, Vol. 55, No. 4, 787-818.

http://dx.doi.org/10.5465/amj.2010.0441

\title{
MODELING HOW TO GROW: AN INDUCTIVE EXAMINATION OF HUMBLE LEADER BEHAVIORS, CONTINGENCIES, AND OUTCOMES
}

\author{
BRADLEY P. OWENS \\ State University of New York, Buffalo \\ DAVID R. HEKMAN \\ University of Colorado, Boulder
}

\begin{abstract}
Although a growing number of leadership writers argue leader humility is important to organizational effectiveness, little is known about the construct, why some leaders behave more humbly than others, what these behaviors lead to, or what factors moderate the effectiveness of these behaviors. Drawing from 55 in-depth interviews with leaders from a wide variety of contexts, we develop a model of the behaviors, outcomes, and contingencies of humble leadership. We uncover that leader humility involves leaders modeling to followers how to grow and produces positive organizational outcomes by leading followers to believe that their own developmental journeys and feelings of uncertainty are legitimate in the workplace. We discuss how the emergent humility in leadership model informs a broad range of leadership issues, including organizational development and change, the evolution of leader-follower relationships, new pathways for engaging followers, and integrating top-down and bottom-up organizing.
\end{abstract}

Sense shines with a double luster when it is set in humility. An able yet humble man is a jewel worth a kingdom.

-William Penn

Within the last ten years, leadership thinkers have increasingly focused on the importance of humility in the context of leadership. The servant leadership (Greenleaf \& Spears, 2002), level 5 leadership (Collins, 2001a, 2001b), and participative leadership (Kim, 2002) perspectives specifically pinpoint the virtue of humility as being critical for leader effectiveness (cf. Weick, 2001). Calls for leader humility have intensified in the wake of corporate scandals attributed to the unbridled ego, hubris, sense of entitlement, and self-importance of the corporate executives involved (Boje, Roslie, Durant, \& Luhman, 2004; Knottnerus, Ulsperger, Cummins, \& Osteen, 2006), and because leader arrogance and narcissism have been identified as reasons why leaders make bad decisions (Chatterjee \& Hambrick, 2007; Dotlich \& Cairo, 2003). As

We would like to thank Jane Dutton, Bruce Avolio, Terry Mitchell, Jim Moats, and Belle Rose Ragins for their helpful comments on drafts. We are also grateful to Peter Bamberger and three anonymous reviewers for their guidance in enhancing the contribution of this study.

Editor's note: The manuscript for this article was accepted for publication during the term of $A M J$ 's former editor-in-chief, R. Duane Ireland. organizational environments become more dynamic, uncertain, and unpredictable, it becomes increasingly difficult for any one leader to "figure it all out at the top," (Senge, 1990: 7); thus, emphasis has shifted to leaders engaging in more "bottomup," humble approaches to leadership (Kerfoot, 1998; Morris, Brotheridge, \& Urbanski, 2005; Vera \& Rodriguez-Lopez, 2004; Weick, 2001). Indeed, the word humility itself comes from the Latin humus, meaning "earth," and humi, "on the ground" (per the Online Etymology Dictionary, accessed in 2010), and thus the term "humble leadership" literally means "leading from the ground" or "bottom-up leadership."

Notwithstanding this call for greater humility in leadership, researchers currently have only a vague understanding of how humble leadership might operate in organizations. Leader humility is still viewed as a rare personality trait that somewhat mysteriously produces favorable organizational outcomes. It is simply not known what humble leadership looks like in terms of an overall leadership posture and way of being, what behaviors it involves, what personal and situational factors determine the effectiveness of these behaviors, or how these behaviors might influence important work processes and outcomes. Lack of clarity about humility in leadership inhibits both further theoretical and empirical inquiry and any potential practitioner application. Because leader humility is new 
to the organizational landscape, in this study we took an inductive approach and asked organization members for humble leader behaviors that they had observed or personally enacted (Edmondson \& McManus, 2007). Our approach was to discover the "lived meaning" of leader humility by learning from organizational leaders themselves about how leader humility operates in organizations.

We seek to piece together the facts obtained from our participants' eyewitness and personal accounts into a conceptual framework of how leader humility is manifested in organizations. We are not attempting to reconstruct every instance of leader humility our participants reported, nor are we proposing a definitive theory of leader humility. Rather, we carefully sampled leaders from many different contexts in hopes of providing a foundational understanding of the meaning organization members attach to the idea of humble leadership. We also seek to determine what they see as important outcomes of this approach to leadership, and the situational contingencies that determine the effectiveness of humble leader behaviors. Thus, we do not see this article as the last word on the topic, but rather actively seek to inspire, call for, and shape future inquiry regarding humble leadership (cf. Payne \& Williams, 2005). We begin by providing a brief, general review of the literature on humility as a virtue and then review what has been said with regard to humility specific to the role of leader.

\section{THE VIRTUE OF HUMILITY}

Humility has been identified as one of the core organizational virtues proposed to provide the foundation for moral action in the workplace and to foster positively deviant behavior (i.e., exceptional performance, altruistic/prosocial behavior (Cameron \& Caza, 2004). Virtues literally connote "moral strength, valor, excellence, and worth" (from the Latin virtutem); and in the context of organizations, virtues such as humility have been generally viewed as that which is good, human, and produces social betterment (Bright, Cameron, \& Caza, 2006: 251). Because humility often entails the recognition and appreciation of knowledge and guidance beyond the self, it is a foundational principle in all major world religions-including Buddhism, ${ }^{1}$ Judaism/Christianity, ${ }^{2}$ Hinduism, ${ }^{3}$ and Is-

\footnotetext{
${ }^{1}$ From a Buddhist perspective, humility is a result of enlightenment and nirvana (Snelling, 1991; Wilson, 2009).

${ }^{2}$ Exemplars of humility in Judeo-Christian religious
}

lam. ${ }^{4}$ Philosophers have also identified humility as a "meta-virtue" that is foundational to other virtues such as forgiveness, courage, wisdom, and compassion (Grenberg, 2005: 133; see also McCullough, 2000). Humility may be foundational to other positive characteristics because, as a "temperance virtue" that guards against excess (Park \& Peterson, 2003), it may temper other virtues, keeping them within the Aristotelian "golden mean" (Crisp, 2000), Buddhist "middle way" (Marinoff, 2007), and Confucian zhong yong ("doctrine of the mean" (Confucius, 2006); it prevents other characteristics from becoming extreme. Though some view humility as merely low self-esteem or an inferior sense of worth or importance-a view that has led at least one prominent philosopher to question humility's worthiness to be called a virtue (Hume, 1994: 219), this conception fails to capture the historically held view of humility as a "classical source of strength" (Tangney, 2000: 70) that captures a person's proper self-perspective (For more extensive reviews of the humility literature, see Exline and Geyer [2004], Grenberg [2005], Owens, Rowatt, and Wilkins [2011], and Tangney [2000]).

\section{Humility in Leadership}

Increasingly, scholars and practitioners have argued the need for today's (and especially tomorrow's) leaders to approach their roles with more humility (Kerfoot, 1998; Morris et al., 2005; Vera \& Rodriguez-Lopez, 2004). For examples, owing to increasing general workplace complexity and requirements for adaptability (Weick, 2001), recent leadership theories have begun to place greater emphasis on the bottom-up aspects of leadership. Some even argue for a need to change "the very idea of leadership-what it is and how it works and even how people even know it when they see it" (Drath, 2001: 124). Researchers have suggested that leaders should move beyond the hero myth or "great man" perspectives on leadership (Murrell, 1997), show their humanness by being open about their limitations in knowledge and experience (Weick, 2001), and focus more on how followers influence the process of leadership (Uhl-Bien, 2006). Leadership writers have increasingly

texts include Moses from the Old Testament (Num. 12:3), Jesus Christ from the New Testament (Mark 10:45; Phil. 2:7), and King Benjamin from the Book of Mormon (Mosiah 2:17, 26).

3 "Hospitality and humility are of the most important values of Hinduism” (Das, 2005: 40).

4 "The first requirement of worship in Islam is to be utterly humble" (Engineer, 2003: 72). 
honed in on the virtue of humility as being at the core of many of these bottom-up approaches to leadership (Collins, 2001b; Matteson \& Irving, 2006; Weick, 2001).

More recently, many fields have called for professionals and leaders to approach their roles with more humility. For lawyers and judges, humility is argued to be important for effectively interpreting the law and balancing the ideals of justice and mercy (McConnell, 1996; Nava, 2010; Scharffs, 1998). In medicine, competence and humility are suggested as the two essential dimensions of medical professionalism (Butler et al., 2011; Gaughan, 2001; Lauer, 2002). Humility has also been spotlighted as important for political (Obama, 2008) and military leaders ("Humility is in style in today's military” [Ruggero, 2009]; see also Hughes, 2010; Meyer, 1997). In the management literature, most of the discussion of humility has also been in the context of leadership. Although a growing number of leadership writers have argued that leader humility is important to organizational growth and survival, it is not totally clear what exactly leader humility is, what it produces, and what influences its effectiveness (e.g., Collins, 2001; Greenleaf \& Spears, 2002; Kim, 2002). This lack of clarity about leader humility is due in part to the fact that the existing literature on this topic is speculative; evidence (qualitative or quantitative) supporting writers' ideas regarding leader humility is lacking. Below we briefly review the existing perspectives in the management literature about the dimensions of leader humility, its outcomes, and its potential moderators that shaped our working hypotheses or substantive theory (Glaser \& Strauss, 1967; Suddaby, 2006) about humility in leadership prior to our data-gathering effort.

In existing perspectives on humble leadership, humility is mainly an innate virtue, or stable personality trait, rather than a set of behaviors that leaders can enact. For instance, some writers have suggested that leader humility involves self-awareness, openness to new ideas, and the tendency to look past, or "transcend," oneself (Morris et al., 2005). Similarly, others have argued that humility entails a willingness to understand the self (strengths and weaknesses) and an orientation toward others more than self (Nielsen, Marrone, \& Slay, 2010). In the servant leadership perspective, leader humility involves the "ability to learn from and gratefully receive the gifts of the less powerful" (Greenleaf \& Spears, 2002: 320), and the level 5 leadership perspective suggests that leader humility involves a lack of charisma, a sense of calmness and quietness, and a baseline assumption that success comes in part from good luck (Collins, 2001b).
In stark contrast with narcissism, which is often described as entailing volatile swings from grandiose to self-abasing self-views (Rhodewalt \& Morf, 1998; Rosenthal \& Pittinsky, 2006), humility has been labeled as a temperance virtue that has a stabilizing or grounding influence on self-perceptions (Park \& Peterson, 2001). Thus, though humility and narcissism are likely to be negatively related, a humble leader is not merely the opposite of a narcissistic one. In addition, since the strong negative emotions of envy and jealousy often hinder the ability to make accurate self-appraisals, scholars have suggested that effective emotional management and awareness are associated with humility (Morris et al., 2005).

Although a great deal of disagreement about the precise leader behaviors that are associated with humility exists, there is some consensus that humility generally involves how leaders tend to view themselves (more objectively), others (more appreciatively), and new information or ideas (more openly) (Exline \& Geyer, 2004; Owens, 2008; Owens, Johnson, \& Mitchell, 2012; Tangney, 2000; Templeton, 1997). We used this general, virtuebased definition as an initial understanding of humility going into our study and examined how leaders' and followers' personal theories of humble leadership overlap with or differ from this virtuebased definition.

\section{Contingencies and Outcomes of Leader Humility}

Leadership styles or approaches can be effective or ineffective depending upon the situation (see Hersey, 1985). We anticipated that there may be circumstances or contexts in which behaving humbly as a leader may be less effective. Because of their absence in the literature, one major aim of this study was to uncover some of the boundary conditions for the effectiveness of humble leader behaviors and to learn when and in what settings participants report humility as associated with weak or ineffective leadership.

Leader humility may foster a less self-interested leadership approach, which is argued to increase followers' liking toward and trust of a leader (Nielsen, Marrone, \& Slay, 2010). Likewise, others have suggested that leader humility may engender supportive leader-follower relationships, an unselfish use of power (Morris et al., 2005), and better decision making (Kim, 2002). The literatures on servant leadership (Greenleaf \& Spears, 2002) and self-sacrificial leadership (De Cremer, Mayer, van Dijke, Bardes, \& Schouten, 2009) suggest that leaders engaging in bottom-up behaviors such as service and self-sacrifice results in followers who are 
better equipped and more committed and organizations that are financially better off (cf. Graham, 1991; Greenleaf, 1977; Spears, 1998). Since few specific outcomes of leader humility have been suggested or empirically examined, we considered exploring the perceived outcomes of leader humility to be an important priority for this study.

This review of the literature provided us with important priorities for examining humility in leadership. Specifically, scholars still only have a vague idea about what leader humility looks like in organizations and do not really understand how leader humility influences followers and work processes and what the boundary conditions are for the effectiveness of humble leader behaviors. Thus, these priorities shaped our inquiry and interview protocol. By asking participants to report specific humble leader behaviors and their perceived outcomes, we sought to gain a richer understanding of the leader humility construct in organizational settings. In this article, we also seek to identify the conditions in which humble leader behaviors are thought to be more or less effective. To that end, we interviewed leaders from a wide range of organizations and leadership levels to examine whether the reported effectiveness of humble leader behaviors depends on the organizational context and other situational factors.

\section{METHODS}

\section{Context}

Because leadership is a highly complex phenomenon steeped in contextual and symbolic interpretations (Conger, 1998) and because new organizational topics benefit from a qualitative foundation (Edmondson \& McManus, 2007), we chose a qualitative research design. Along with other interpretivist researchers, we view leadership as a socially constructed phenomenon. It is actively created through social interchange (Walsh, Henderson, \& Deighton, 1988) and over time yields a collective frame of reference (Daft \& Weick, 1984) that becomes a dominant logic or reality for collectives (Gephart, 1984). As leaders engage in their own leadership roles, they become careful observers of how other leaders behave and experiment with the leadership behaviors and approaches they observe (Armstrong, Allinson, \& Hayes, 2002). Because most leaders are simultaneously followers (i.e., they are both "senders" and "receivers" of leadership behaviors), leaders are ideally positioned to gain insight about humble behaviors, enacted or observed, and the effects of these behaviors in the workplace.
What we view as sorely lacking from the literature on humble leadership are rich, "real-life" accounts of what leader humility looks like and the boundary conditions for leader humility. We were interested in exploring not only what leader behaviors are viewed as humble, but also the meanings (i.e., mental models or personal theories) of these behaviors and their observed outcomes in different leadership contexts. Thus, in line with Eisenhardt (1989), we employed a case study approach with follow-up interviews from multiple contexts because it offers the prospect of producing results that are less likely to be deemed to be idiosyncratic to one case and allows for richer theoretical inferences. Though the approach of drawing from multiple contexts is the most common qualitative approach in leadership research (Bryman, 2004), it is not employed for purposes of generalizability, but because it allows researchers to observe more interesting differences among contexts and boundary conditions.

\section{Data Collection}

Theoretical sampling. When selecting our initial sample in which to begin to explore humble leadership, we took cues from our review of the leader humility literature, which suggests that a more humble approach to leadership might be fostered by a leader going through significant adverse challenges, feeling powerless or not in control, and making mistakes (Collins, 2001a; Exline \& Geyer, 2004). When we began our study in the summer of 2007, the housing bubble was bursting, as home sales and prices experienced historic declines (Trejos, 2007). The regional mortgage bank whose employees we sampled was facing significantly lowered financial success, and the entire industry was facing a social stigma for being seen as contributing to an economic recession via irresponsible lending practices (Poirier, 2007). The industry was described as "humbled" by current circumstances (DeSilver, 2008; Goodman \& Morgenson, 2008). Leaders confirmed that they had feelings of uncertainty and lack of control amidst "unprecedented changes" (interview no. 2) and that their business was "being tested as much as you can be tested ... with competitors going down every day" (interview no. 2).

The adverse changes, uncertainty, and feelings of lack of control prevalent in the industry led us to view a large, northwestern United States mortgage banking firm as a theoretically meaningful context in which to begin exploring humble leadership. At this firm, we interviewed 17 leaders from four different hierarchical levels (from regional president 
to branch manager); visited the corporate headquarters and 14 outlying offices; recorded and transcribed roughly 200 single-spaced pages of field notes about observed leader-follower interactions in meetings, contextual artifacts, and musings before and after each interview; and held multiple face-to-face interviews with an outside leadership consultant who had been training the firm leaders for over a year prior to the interviews. We were exposed to leader training meetings, discussions of "360 degree feedback," day-to-day interactions with employees, and leaders' collaborations with their peers to work to overcome common challenges. Since we had access to the 360 degree evaluation scores, which contained questions such as "demonstrates personal humility," we paid particular attention to the perspectives of those who were rated highly by others on this item. We also reviewed archival leader assessments and financial performance data for a two-year period. Though the leader interview data gave us the richest view of the phenomenon, the other forms of field data shaped our interpretations of the first round of interviews and our emerging theory about humble leadership.

Our ongoing analysis of the first round of interviews and field notes yielded the insight that power significantly influenced humble leader behavior. Level of power centralization is a core dimension of organizational culture (Burns \& Stalker, 1961; Cameron \& Quinn, 2005), and power is a basic underlying dimension of human relationships (Fiske, 1993). Because humility represents a bottom-up type of leadership, we wanted to examine whether it operated differently in power-centralized versus power-decentralized organizations. Thus, our subsequent sampling decisions were shaped by our desire to know how humble leader behaviors differed in organizations in which power was generally more centralized and those in which it was typically more evenly distributed. In our second round of interviews we interviewed leaders from organizations in which power is traditionally more centralized (seven military leaders and three manufacturing/industrial leaders); leaders from other organizations in which power is traditionally more spread out (five high-tech firm leaders and eight hospital leaders); and yet others from organizations in which the power distribution is typically somewhere in between the two more extreme types (seven leaders in financial and retail service companies). Religious organizations were also an intriguing context to us, as they typically have more hierarchical structures (Brinkerhoff, White, Ortega, \& Weitz, 2007), while also promoting virtues such as humility. Thus, we interviewed eight leaders from religious contexts in hopes of documenting important insights about the boundary conditions of leader humility.

The first author approached leaders from each organizational type and used a snowball sampling technique to secure further interviews in each organization, until theoretical saturation was reached. In all interviews, we sought to sample leaders from different levels (16 CEOs, presidents, high-level executives; 20 midlevel leaders; and 19 frontline leaders) to observe any differences in humble behaviors and their impact based on factors such as leader visibility and the degree to which the leader's influence was symbolic (usually seen at higher levels of leadership [see Conger, 2000]) or mainly interpersonal. Because most organizational leaders are male, only nine of our participants were female $(16 \%)$. By the seventh interview with a female leader we began to feel we were reaching saturation with regard to differences in perceptions across leader gender. We sought out two more interviews with female leaders to make sure. On average, our participants were 44.20 years old, had worked 4.40 years for their current organization, and had 17.05 years of experience in their industry. A summary of demographic information for the groups of participants is given in Table 1.

Procedure. Drawing on our literature review, we created an interview protocol aimed at eliciting anecdotes or critical incidents of humble leader behavior and its consequences and contingencies. The bottom of Figure 1 includes a sample list of questions from this protocol. Interviewees shared examples from their own leadership and their observations of those they considered to be humble leaders. For contrast, many interviewees also shared examples of what humble leadership is not, accounts based on times when they or another

TABLE 1

Interview Sample Information

\begin{tabular}{|c|c|c|c|c|c|}
\hline Wave & Context & $n$ & $\begin{array}{c}\text { Average } \\
\text { Tenure as } \\
\text { Leader }^{\mathrm{a}}\end{array}$ & $\begin{array}{l}\text { Percent } \\
\text { Male }\end{array}$ & $\begin{array}{l}\text { Percent } \\
\text { Upper- } \\
\text { Level }^{\text {a }}\end{array}$ \\
\hline 1 & Mortgage banking & 17 & 4.36 & 59 & 35 \\
\hline 2 & High-tech firm & 5 & 5.00 & 100 & 80 \\
\hline 2 & Hospital & 8 & 4.17 & 50 & 25 \\
\hline 2 & $\begin{array}{l}\text { Financial services/ } \\
\text { retail }\end{array}$ & 7 & 9.00 & 86 & 57 \\
\hline 2 & Religious & 8 & 4.46 & 88 & 29 \\
\hline 2 & $\begin{array}{l}\text { Manufacturing/ } \\
\text { industrial }\end{array}$ & 3 & 6.89 & 100 & 87 \\
\hline \multirow[t]{2}{*}{2} & Military & 7 & 7.07 & 100 & 57 \\
\hline & Total & 55 & 5.48 & $16 \%$ & $29 \%$ \\
\hline
\end{tabular}

\footnotetext{
${ }^{\mathrm{a}}$ In years.

${ }^{\mathrm{b}}$ Reflects senior and executive positions in organizations (i.e., above middle management).
} 


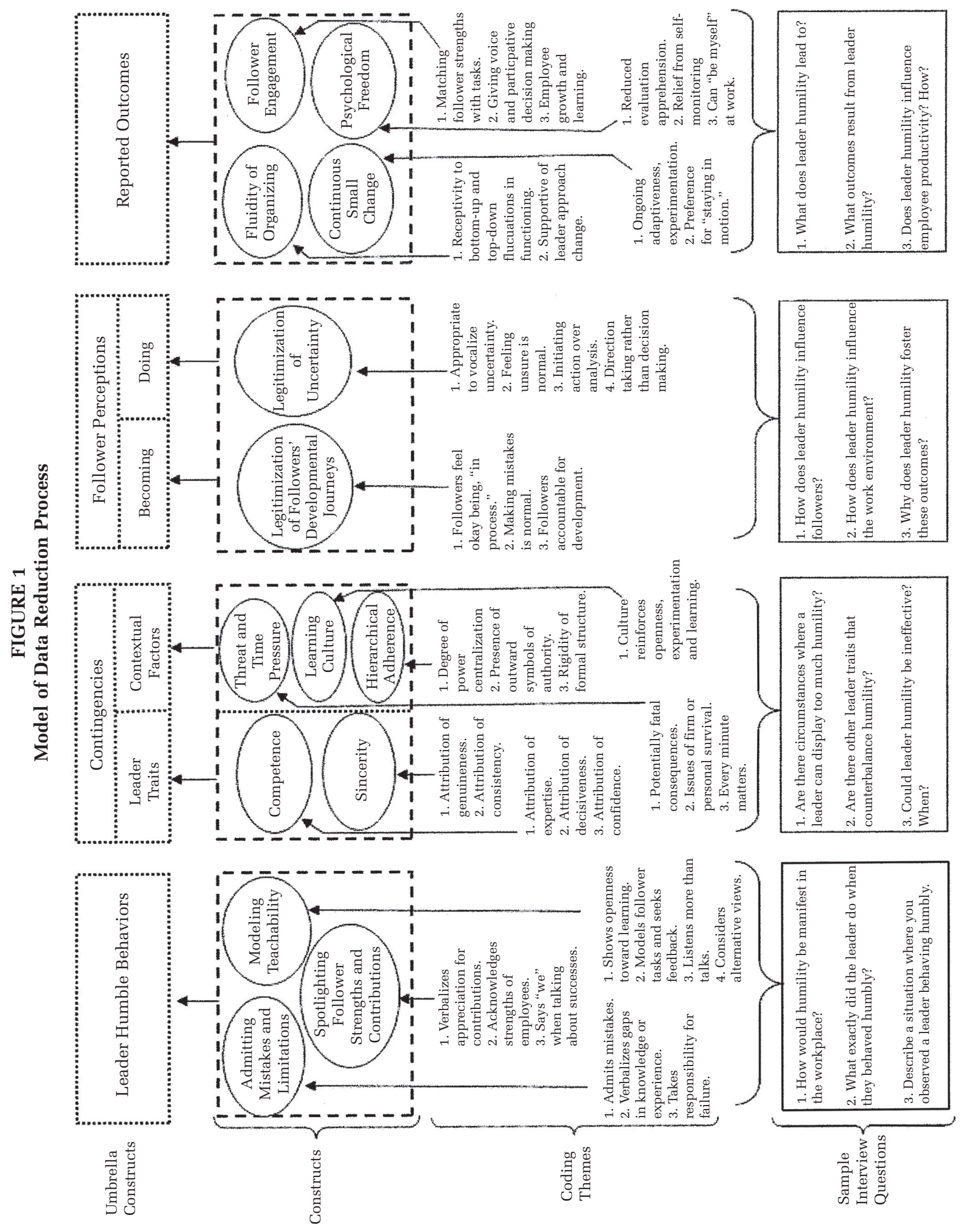


leader displayed what they viewed as the opposite of humble leadership. All of these responses were useful in formulating our conceptual model. The self-reported examples provided more insight into the intrapersonal processes of humble leadership (i.e., beliefs underlying humble behaviors) and the personal outcomes resulting from a leader behaving humbly (i.e., psychological freedom), and the observed examples provided more insight into how these behaviors were interpreted (i.e., follower perceptions) and the interpersonal results of humble leader behaviors. Though generally we observed a lot of convergence of self-reported and other-reported perspectives of humble leadership, there were some key differences, which we discuss below.

Because past research suggests some associate humility with humiliation and self-contempt (Exline \& Geyer, 2004; Grenberg, 2005), in the course of the interviews we felt it was important to provide a common frame of reference for participants by giving each leader the general, strengths-based definition of humility noted in the introduction. However, to ensure we were not unduly priming respondents' descriptions of leader humility, we experimented with not mentioning the definition until the middle or end of the interview, and in some interviews withholding the definition altogether. We also couched the definition in the question "This is how academics define humility, but what does humility mean to you in the context of leadership?" We did not observe any significant difference in the frequency with which interviewees mentioned each of the humility behaviors we uncovered in these interviews. We also found triangulated evidence for the humility behaviors we uncovered from our first sample's 360 degree evaluation data, which we report below. Each interview lasted approximately 60 minutes and was recorded and transcribed verbatim. As an accuracy check, we sent 30 interview transcripts to participants. Though several leaders said they appreciated the opportunity to revise their statements, we received no corrections. We took this as a signal that the transcriptions were ready to be analyzed.

\section{Data Analysis}

We conducted a theme analysis (Lee, 1999; Miles \& Huberman, 1994) and obtained an agreement analysis by independent coders (Cohen, 1960). Following Boyatzis (1998), our search for themes was initially sorted into rough umbrella constructs that appeared to adequately capture the humble leader behaviors, outcomes, mechanisms, and contingencies emerging in the data. Over a series of weekly meetings, we iteratively generated 39 subthemes or codes until we had a set of themes within which each response could be categorized. Two other research assistants were then given these codes and asked to categorize all interview statements. ${ }^{5}$ The coders independently coded 84 percent of incidents identically and then resolved discrepancies via discussion. Cohen's kappa from this round of coding was .81, which, according to Landis and Koch's (1977), indicates "full agreement." 6

Since our intent was to learn about both the similarities and differences in humble leadership in different organizational contexts, we then organized all interview statements into coded categories by organization type. We anticipated nuanced differences among types, as the implementation of leader humility would interact with different situational demands, social expectations, and follower implicit theories of leadership. Over a series of meetings, we discussed and made note of differences in the subjective meanings attached to leader humility (Schutz, 1972) and the different contextual contingencies mentioned.

\section{Overview of Conceptual Model}

The purpose of Figure 1 is to summarize how we organized, reduced, and interpreted our data. The bottom row in the figure lists sample questions that guided each interview; the next row lists the codes used to categorize responses to these questions; the next identifies our model constructs; and the last (top) row states the umbrella constructs that reflect the major organizing components of our model. Our first set of constructs is organized under the umbrella construct "Leader Humble Behaviors." Participants reported why or how (i.e., "Follower Perceptions") these behaviors led to the outcomes they cited (i.e., "Reported Outcomes"), as well as what factors influenced the effectiveness of these behaviors (i.e., "Contingencies"). These linkages, themes, constructs and umbrella constructs provide the structure for the presentation of our findings and the foundation for the conceptual model that emerges from our results.

\footnotetext{
${ }^{5}$ Reviewers requested that we not report frequencies for every code. We do report, however, that all of our codes were cited in at least 16 percent and up to 85 percent of all interviews.

${ }^{6}$ The Atlas.Ti program aided us in organizing and coding our qualitative data.
} 


\section{HUMBLE BEHAVIORS AND CONTINGENCIES}

In this section, we report the elaborative insights we documented about the enactment of humble leadership; these are insights intended to go beyond that which currently exists in the humble leadership literature. Though the interview descriptions of humble leadership were full of nuanced differences, these humble leader behaviors meaningfully fit into three general categories: (1) acknowledging personal limits, faults, and mistakes, (2) spotlighting followers' strengths and contributions, and (3) modeling teachability.

Our participants also reported many contextual and personal factors that influenced the appropriateness and effectiveness of humble leader behaviors. Responses to our questions about when behaving humbly would be less effective varied from mentions of leader traits counterbalancing humility (i.e., behaving humbly will be effective only if followers perceive their leader to be generally competent or sincere), to more contextual features, such as the presence of extreme threat and time pressure, an organizational culture of learning, or level of adherence to hierarchy. Table 2 presents sample quotes illustrating each contingency construct. For the sake of narrative flow, in this section we discuss the humble behaviors and the most often cited boundary conditions and contingencies that were mentioned in reference to each of these behaviors. We have emphasized particularly illustrative wording in the interview quotes with italic. At the end of this section, we summarize by discussing what we view as the "core essence" or "way of being" captured by humble leadership, as revealed from the interview data.

\section{Acknowledging Personal Limits, Faults, and Mistakes}

When describing humble leaders, participants reported examples of leaders acknowledging personal limits, faults, and mistakes. From the accounts, humble leaders did not seem to be oblivious or blind to their strengths (i.e., "Humility is knowing what you are good at and not good at" [interview no. 3]; "She was completely open to both strengths and weaknesses" [interview no. 50]), but it was publically owning up to mistakes and acknowledging limits that formed much of the "quiet charisma" and strength of humble leaders. Expressing a perspective contrary to the romanticized or "great man" perspectives on leadership, wherein leaders are often viewed as superhuman heroes, our interviewees suggested that the humble leaders' unique strength involved having the cour- age to show their "humanness" to followers, including admitting personal foibles, knowledge gaps, lapses in judgment, and bad decisions, and generally acknowledging when they did not lead well. Sample statements include "He never professed to be an expert at something he wasn't" (interview no. 41); "He is aware of his limitations. He understands what others are strong at and what he is weak at" (interview no. 44); and "He poked fun at himself. He never tried to appear more perfect than he was" (interview no. 34)

In some cases, admitting weaknesses was accompanied by leaders requesting followers to help them remedy a weakness or compensate for it:

In one training, I announced to my direct reports, "I am not a good listener. I just charge ahead. And so, that's something that I need you to help me with because I'm just not good at it. When we're in these meetings and we're being collaborative, help me to remember to just be quiet and shut up for a bit and let people hammer out ideas." (interview no. 15)

My leader does a good job of letting us know her weak spots. She lets us know how we can help to compensate for the things she doesn't do very well. (interview no. 42)

Humble leaders were also described as accepting blame for failures. For example, one participant reported, "We were not doing well and we all knew it. . . The leader was very forthcoming and upfront about assuming fault for that in front of everyone" (interview no. 22). In both the interviews and our observational data of those others described as humble leaders, we found evidence of their not only taking responsibility for their own mistakes, but also for those of their teams, owning that it was their role to adequately prepare, guide, and provide enough resources for the teams to succeed.

The above examples focus on humility "looking back," such as admitting limitations from past experience or assuming blame for past failures, but some leaders also reported that behaving humbly involved leaders acknowledging when they were losing control of their emotions in real-time interactions. Interviews suggested that humility also involved recognizing when to disconnect from an interaction and let a "cooler head" take care of a tense situation (interview no. 10). For example:

Humility gives us the ability, not only to recover quickly when we are getting too emotional but to allow other people to know, "Hey, I just have to let you know I need to step aside for a moment or you need to have a little patience with me right now, because I'm not myself." Even with my husband, to say "I just need a moment. I need to process this. I need to get myself back to a good place." (interview no. 11) 
TABLE 2

Evidence for Humble Leader Behavior Model Constructs

Umbrella

Construct

Humble behavior

Humble behavior

Follower

perception

Follower

perception

Reported

outcomes

Reported

outcomes

Reported

outcomes

Reported

outcomes

Contingencies

(leader traits)

Contingencies

(leader traits)

Contingencies (contextual

factors)

Contingencies (contextual factors)

Contingencies

(contextual

factors)

Construct

Examples

Acknowledging limitations, fault, and mistakes

Spotlighting follower strengths and contributions

Modeling teachability

Legitimizing follower development

Legitimizing uncertainty

Relational trust and loyalty

Psychological freedom

Follower engagement

Small, continuous change

Leader competence

Leader sincerity

Extreme threat and time pressure

Organizational learning culture

Hierarchical adherence
I made a business decision where I put something in place, went forward and then got feedback it was not working. And I said, "You know what, I messed up. We need to redo this." I just tried to be upfront and honest that I had made a mistake and that we needed to redo it. (interview no. 16)

This incredibly complex project was delivered as a huge success and the leader gave everybody on the team all the credit. (interview no. 23)

When there was a success among the team he made sure the person who did the work gets due recognition. He will make sure they get noticed. (interview no. 29)

And so that humility has helped me ... listen to others and allow them to ask questions and then to respectfully go about answering them. (interview no. 11)

Even though he had the ability to run things well on his own, he would still ask input and advice from his staff. (interview no. 31)

I have always stressed with the people who report to me that it is OK to make a mistake. They quickly realize that most mistakes don't cost us that much and we fix it and move on. We learn from it and make the whole process better as a result. (interview no. 4)

I tell followers that the changes we are facing are unprecedented and there is no history to fall back on. But that we don't need to fear. We'll just make the best decisions we can and execute. (interview no. 2)

Humility builds loyalty. That was the difference between me and my peers. My leadership approach fostered loyalty; that was my brand. (interview no. 55)

You may get the job done without humility but people don't seem to be happy. (interview no. 54)

Coming from a spirit of humility allows you to be more of yourself and drop those guards. (interview no. 9)

With humility, you don't feel the pressure to be the expert at everything. Takes the pressure off. (interview no. 17)

Employees walk away with more sense of responsibility and accountability. In some ways, his humility actually increased pressure to perform. (interview no. 41)

I think [humility] increases the rate of adjustment because you are probably more open to outside criticism or ideas or the external environment and I think that's what's needed to help improve adaptability. (interview no. 3)

Good leadership is a constellation of several positive traits. Humility is definitely one of them. But a leader who is humble without competence won't do well. There has to be a reason for followers to follow this leader. So humility might be considered the icing on the cake. (interview no. 34)

[Leaders] sometimes try to manipulate people by acting humble and I think most people figure it out fairly quickly. ... If they figure out who you really are and you are not faking it and you are humble, then they are more willing to accept it. (interview no. 10, emphasis added)

Your humility has to be real in order for it to work. (interview no. 16)

In environments were decisions need to be made quickly a humble leader may not be able to make them as quickly. There are some situations where humility is not good, like when timeliness is everything. Situations of timeliness which don't call for quality; in these circumstances it's possible a humble leader couldn't get it done. When you need to get your soldiers over the hill, it is not a time to get opinions. (interview no. 34)

Our collaborative culture is a strength of our organization. This culture has been set by our CEO and filters down from there. I would say this allows for humility to play into what we do. (interview no. 2)

As a military leader, you can't be humble all the time. At times you have to be aggressive and mean what you say and say what you mean. (interview no. 52)

I think that leader humility would clash more with a command-and-control type culture. (interview no. 2) 
Following up on this idea, we asked leaders in subsequent interviews for insights about the emotional expression and emotional regulation of humble leaders. In all subsequent interviews, humble leaders were described as regulating their emotions well, handling anger or stress well, or only showing positive emotions. Thus, the "lived meaning" of humble leadership seems to extend to the domain of emotional management, enabling humble leaders to acknowledge when harmful or counterproductive emotions are getting the best of them in real-time interactions.

Self-reported accounts suggested that these behaviors were motivated by a belief that being human and showing humanness toward followers yields better interactions and more solid relationships than being (or trying to appear) "perfect." For instance, "I think it's essential [for humility] that your direct reports not see you as having an 'I'm perfect, I sit on a golden throne, I'm upper management' mentality" (interview no. 8). "It's important that [followers] know that I don't think I'm perfect. If I make a mistake, and I don't acknowledge it, there's no buy-in on their part. So I'm going to try to lead by example, but I'm also going to make it known that I'm going to make mistakes" (interview no. 1). Humble leaders, it seemed, are less susceptible to the trap of believing their position makes them immune from having to acknowledge weakness or admit mistakes (Burke, 2006).

\section{Contingency: Perceived Competence}

The accounts suggested that humility was effective only to the degree a leader was also perceived as competent or able, especially with regard to the behavior of admitting mistakes and limitations (interviews nos. 34 and 51). Though humbly admitting weakness was itself described as a unique type of strength, our participants also insisted that more traditional leadership traits, such as intelligence, resolve, and persuasiveness, needed to work in tandem with humility for the leader to be effective. Looking closely at our accounts, we noticed that these attributions of competence in many cases depended on external signals of authority. For example, among those with a highly visible leader role (CEO or executive) or clear, external signs of authority (military chevrons on a uniform, religious regalia), the competence of a leader who displayed humble behavior was less likely to be called into question than would be likely in the case of a lower-level leader, for whom signs of leader authority were lacking or more ambiguous.

Humility could be perceived as weakness unless the leader also is perceived as confident and effective.
It's less important if you have a lot of positional power, like a CEO, but for somebody at my level competence matters a lot. If followers are turned off [i.e., don't see you as competent], humility will make you less effective. (interview no. 1)

Our data also suggested that demographic differences influenced perceptions of competence as moderators of the effectiveness of humility. Younger leaders with older followers believed they first needed to "prove themselves" (interviews nos. 9 and 54), to build up or establish reputations for competence, before admitting weaknesses. Without this reputation, behaving humbly by admitting mistakes and limitations was seen as too "risky." For example, one younger leader promoted to lead a group of older employees said:

As much as I want to show my people the real side of me, I risk not living up to their expectations. I risk them seeing me weak in some way. I risk showing that I am susceptible in some way. I risk opening the kimono and showing them something they don't want to see. I risk all of these different things. So I very much grapple with that on a daily basis. (interview no. 13)

Similarly to young leaders of more experienced followers, the female leaders we interviewed also felt this tension between behaving humbly and establishing a reputation for competence. In line with past research on emotional display (Tiedens, Ellsworth, \& Mesquita, 2000) and agentic behaviors (Rudman \& Glick, 1999), the woman leaders we interviewed often experienced a double bind when trying to simultaneously meet gender role expectations and leader role expectations (Eagly, 2007; Eagly \& Karau, 2002; Ragins \& Winkel, 2008). It seemed that with regard to humility, female leaders operate in a more narrow range of acceptability, feeling pressure to be a strong leader on the one hand and a humble female on the other:

What I've learned is that if you're a female people expect different things. I think humility is expected more for a female leader than a male leader, but they need to see you as competent too. As a woman leader that's a complex one for me. I've tried to dig deeper in this one. I'm petite and I look younger than I am and I'm a female, so I look back at certain events as a leader and go "Gosh, did that commandand-control approach come from me because I thought I needed to prove something?" I've gotten comments from other males like, "Gosh, I used to think you were so cute and sweet." (interview no. 14)

Several interviewees echoed this idea that nonhumble female leaders are viewed more negatively (described as "overcompensating"; interviews 
nos. $3,5,6,53$, and 54), whereas nonhumble males were more likely to be viewed as courageous, confident, competent, or strong. In contrast, our data suggested that when men show humility they are less likely than women to be socially penalized and instead are more likely to be admired. A male interviewee said, "In our society, women are expected to be more humble. Males are given more credit when they are humble" (interview no. 20). Statements from both male and female leaders indicated that they saw a sense of injustice in the tendency they had observed to expect females to behave more humbly and then to question their competence for doing so (interviews nos. 3, 7, 10, $11,14,16,34,51$, and 53).

Overall, social status differences based on age and gender were reported as important determinants of competence perceptions and the perceived effectiveness of leader humility expression, especially with regard to acknowledging mistakes and limitations. ${ }^{7}$ Surprisingly, the influence of age and gender was described as less impactful in military settings for shaping competence perceptions because the clear hierarchical rankings and positions (i.e., uniform chevrons and bars) give strong signals of credibility. "Though I think female leaders have to prove themselves more, there are lots of other ways to differentiate people. Military rankings, for instance, influence attributions of competence as much as or more than gender or ethnic status" (interview no. 54). Our accounts suggest that lowerlevel leaders, younger leaders, and female leaders may be more reticent to display humility by admitting mistakes and limitations because their competence is more likely to be called into question.

Also, nearly all of those in business contexts mentioned competence as an important precondition for admitting weaknesses, whereas not one religious leader mentioned competence as an important precondition for the effectiveness of leaders humbly admitting weaknesses. We interpreted this finding to mean that perhaps humility is considered one of the core competencies of religious leadership (i.e., central to follower expectations of religious leadership), whereas in a business environment, humility is more likely to be viewed as an

\footnotetext{
${ }^{7}$ Past research has shown that the feeling of social standing or interpersonal power stems from factors such as gender, age, and ethnic status (status characteristics theory [Berger, Fisek, Norman, \& Zelditch, 1977; Wagner \& Berger, 1997] is relevant here) and that different standards are used to judge the behaviors of more powerful and less powerful group members (Biernat \& Fuegen, 2001).
}

"extra-role" behavior that supplements the core competencies of business leadership.

\section{Spotlighting Follower Strengths and Contributions}

Humble leaders were also described as being very deliberate in communicating the specific value that their followers had to a team or an organization. In contrast to "nonhumble" leaders, who were sometimes described as suspicious toward and threatened by exceptionally intelligent or talented followers because they were worried these followers might "outshine" them (interview no. 10), humble leaders instead were intent on pushing their followers into the spotlight. These leaders frequently recognized, appreciated, and praised followers' strengths and complimented the work and efforts of followers. Humble leaders were described as students of their followers' strengths, and thus they were experts on the "human capital" around them. They actively engaged in behaviors to make these strengths known and salient to others. For example: "It was obvious that she knew followers' strengths and she even structured zone goals based on that knowledge. She always gave them genuine compliments" (interview no. 21). Rather than drawing attention to themselves, humble leaders were described as using "we" rather than "I" when talking about the leaders' accomplishments. For instance, one interviewee highlighted giving credit to the team rather than taking credit for himself as the behavioral change that marked another leader's transformation from being arrogant to humble:

I left one of my last companies because of my leader's arrogance. . . . He was taking my ideas and coining them as his own to upper management. He had all the answers to everything in his mind's eye. He thought he had no weaknesses. So I left. But I just had a conversation with a couple of my previous coworkers and they said "He's changed." They said he'd received some tongue lashings from upper management that made him more humble and now he always talks in terms of "we," like "As a region we're doing this and we're making this happen and we, we, we." I think he learned to be humble. (interview no. 8)

Humble leaders were described as attributing good ideas to followers when presenting to upper management, taking money out of their pocket to give to followers who had done a good job (interview no. 49), giving genuine rather than empty praise, and taking notice of the unique strengths of followers (interview no. 25). Overall, humble leaders seemed to be continually shifting attention for 
positive events to others and shifting focus for negative events on themselves.

\section{Contingency: Perceived Sincerity}

Participants reported that the behavior of spotlighting follower strengths and contributions was effective only if leaders were viewed as sincerely offering praise. Humble leaders were described as those who provided honest substantive compliments, described true follower strengths, and genuinely appreciated the contributions of others. As one leader described, "She always gave genuine compliments and never handed out flattery or empty praise-it was real praise" (interview no. 21). In contrast, descriptions of attempts to portray "false humility" or "instrumental humility" were accompanied with contempt and suspicion. Leaders who went "through the motions" of appearing humble by handing out false praise in a disguised attempt to win favor were not well regarded by followers. Moreover, false humility was reported as putting followers into a defensive and cautious mind-set. For example, a military leader told us, "I have seen a leader fake humility for their own benefit. When they are just going through the motions you lose respect for them and really distrust everything they say" (interview no. 55). As Schimmel said, "In a society which rewards humility with social esteem, some people may mimic behaviors typical of authentic humility" (1992: 39).

Concerning sincerity, we asked about what our participants viewed as the connection between leader humility and authenticity, a topic that has recently gained more attention in the leadership (Avolio \& Gardner, 2005), emotions (Hareli \& Rafaeli, 2008), and customer service (Grandey, Fiske, Mattila, Jansen, \& Sideman, 2005) literatures. Though some felt that authenticity and humility were deeply intertwined (i.e., "The willingness to be authentic first comes from a place of being humble" [interview no. 2]), others felt they were not necessarily connected, citing examples of leaders who were "authentically arrogant" (i.e., "I've had leaders who were authentically arrogant. They really believed they were superior to others" [interview no. 34]; "You can be a person who is selfcentered and authentic about it. ... These concepts [i.e., humility and authenticity] are not necessarily intersecting” [interview no. 5]). Thus, for many, authenticity was perceived as the motive for a leader's behavior (regardless of the type of behavior), but humility was seen as reflecting a certain set of leader behaviors. Notwithstanding some disagreement about the conceptual similarities and differences between leader humility and the general con- cept of authenticity, ${ }^{8}$ there was consensus that leader humility was better received if it was seen as sincere or authentic.

\section{Modeling Teachability}

In the descriptions of leader humility we gathered, perhaps the most central element of humble leader behavior (i.e., the one most often mentioned and emphasized by followers) was that humble leaders were described as "models of learning." Humble leaders showed openness to new ideas and information, had a habit of listening before speaking, and were very receptive to feedback. For example, "The leader would always take notes in meetings when others were talking. He really listened to people" (interview no. 4). "This leader was very good at learning new things . . . a good listener" (interview no. 38). The leaders' self-reported accounts of humility suggested that debunking the belief that a leader has to have "all the answers" enabled listening to others and showing an openness to feedback. Instead, the leaders suggested that believing that everyone has much to learn fostered the behavior:

You can't go into a conversation where you learn without a level of humility. If you've got a mentality like "Wow, I don't have to know it all and I don't have to be perfect and it's okay for me to admit that"-that's how you can go into a conversation and really learn from somebody else. You can't learn from others if you think you already know it all. (interview no. 17)

Humble leaders were often described as receptive to the feedback and ideas of others because humility entails "recognizing there are a lot of different ways to accomplish something" (interview no. 55). Interviewees reported that stressful situations and failures were often resolved by a leader listening to followers and seeking their input to cocreate solutions to challenges.

Humble leaders would also model teachability by initiating role reversals with followers-that is, assuming the follower role and putting the follower in the leader/trainer role. Rather than merely telling followers how to do things, humble leaders were described as modeling follower tasks and then seeking feedback from the follower. For example:

\footnotetext{
${ }^{8}$ We recognize that the term "authenticity" used in this conceptual comparison exercise is referred to in the general sense and does not reflect the specific dimensions of the authentic leadership construct (see Walumbwa, Avolio, Gardner, Wernsing, \& Peterson, 2008).
} 
The leader would actually step into the role and say, "Hey let's learn this together." . . . "Let's go out and make some sales calls together. Maybe you can see me making a call and you can give me some pointers in what I do right, and what I do wrong. Then you can try it." (interview no. 17)

Several interviewees described humble leaders as being willing to "get off the golden throne" (interview no. 8) and "jump in the trenches" (interview no. 40) to learn firsthand the challenges followers faced. It seemed that no follower task was too menial for humble leaders. They would model all kinds of follower tasks, from sales calls (interview no. 17, 19) to custodial work (interview no. 51) to grunt labor (interview no. 54). In one example, a higher ranking military leader broke his leg helping lift a heavy generator off a truck with his soldiers. His only lament was that he would not be able to run with his soldiers for a while (interview no. 53). Through modeling, humble leaders seemed intent on fostering a positive, proactive attitude about learning new things and gaining deeper understanding about how to best help followers overcome challenges.

Contingency: Extreme Threat and Time Pressure. Participants reported that the effectiveness of humility in general, and modeling teachability especially, depended on their organization's culture as well as the contextual circumstances leaders faced. Specifically, we learned from our interviewees that modeling teachability was less effective when the status quo had been seriously disrupted, time for action was short, or followers faced a significant threat. In such situations, followers were described as needing "restabilization" (i.e., reestablishment of order) more than development, appreciative comments, or the opportunity to express themselves and be listened to. For instance:

While humility is important, I don't think it is applicable in every situation. Sometimes [behaving humbly] is not what followers need, because they may be feeling their own insecurities. It's a very isolated instance because I believe in humility in almost everything, but I can see in certain situations where you have extreme change and insecurity, when followers may be looking to their leader for self-confidence. The leader needs to step up and truly exhibit themselves. Then the leader can go home and privately freak out. (interview no. 10)

Interviewees explained that modeling teachability and taking a more humble approach to leadership takes time, but that in these high-threat situations in which immediate action was necessary, taking the time to learn and grow would be ineffective. For example:
In the military, sometimes you have to get your soldiers out of there as fast as possible, whatever it takes to get them out of there. In some organizations and situations you just have to go. When time is scarce or it is the critical resource and every tick of the clock means something important, during those times being humble is not the best. (interview no. 51)

Humility in leadership is not a good idea when the safety of the population is at risk with disease control. Here people's lives are at stake and you have to move fast; humility cannot always be present, [you] have to be assertive. (interview no. 22)

Statements from our participants suggest that in situations of extreme time pressure or threat, enacting humble behaviors would be counterproductive and might cause followers to question a leader's worthiness to lead in that situation. As one contextual difference, we found it interesting that not one religious leader could think of a situation in a religious context in which humility would be less effective. This fits with the idea that humility is perhaps more central to religious leadership than to business or military leadership and also suggests that extreme threat accompanied by time pressure is less common in religious contexts.

Contingency: Learning culture. Our participants also mentioned that the overarching culture of the organization in which a leader and followers interact influenced the interpretation and perceived legitimacy of modeling teachability, and some specifically said that this behavior was more effective in an organizational culture that encouraged and reinforced learning. For example:

The values of the organization are important for determining whether humility is recognized as a strength rather than a weakness. ... I think humility depends upon what type of upper-level leadership you have or what type of organization that you are in. One of the things that I see at this company is they allow their managers to take those risks and are learning-focused. I see this culture as fostering more humility and loyalty. (interview no. 5)

According to the interview statements, the behaviors of top-level leaders in an organization had a large impact on shaping a learning culture and validating humble leader behaviors for the lowerlevel leaders. ${ }^{9}$ As top-level leaders became known for modeling teachability, this behavior became symbolic of the culture of the organization and was

\footnotetext{
${ }^{9}$ This idea is in keeping with upper echelons theory (Hambrick \& Mason, 1984), cascading leadership (Yukl, 2010: 486), and leader-imprinting theory (Ballinger \& Schoorman, 2009; Ritter \& Lord, 2007).
} 
the means of legitimizing this behavior for lowerlevel leaders. One humble executive leader reinforced this learning culture role by encouraging organizational members to vocalize their concerns about the leader's decisions, "welcoming debate" (interview no. 14), encouraging collaboration by saying "one of us is never smarter than all of us" (interview no. 2), and emphasizing "openness and teachability" when socializing and training new leaders (interview no. 8). One interviewee described the learning culture that was "catalyzed" by this executive leader's humble example and leadership. She described how after one regional training meeting, leaders from across the state voluntarily huddled in groups, pulled out notebooks and spreadsheets, and engaged in serious conversations about ideas for solving local challenges: "They all could have gone home, but instead most everyone stayed for over an hour helping and learning from each other. In all the previous companies I've worked for in this industry, I have never seen anything like this" (interview no. 8). This interviewee said that the learning culture fostered by this executive leader made it acceptable for middle and first-line leaders to admit where they were struggling and seek to learn from others to find solutions to challenges. She indicated that in other companies where she had worked, humble leader behaviors such as modeling teachability would not have been well received because of the culture of competition and rivalry that existed.

Contingency: Hierarchical adherence. We also found that the degree to which organizations were reported as having a hierarchical culture influenced the expression of all three types of humble behaviors. At the onset of this study, we expected leader humility to be more countercultural-that is, in violation of role expectations in organizations that more rigidly adhere to a hierarchical structure. The emphases on chain-of-command, norms of power centralization, and the presence of explicit signals of leadership authority (number of chevrons, bars, or stars on a military uniform; robes and clerical collars in religious organizations) in hierarchical organizations all reinforce top-down functioning and "power distance" norms. Thus, viewing humble leadership as more of a bottom-up style of leading, we expected it would look different or be expressed less often in hierarchical contexts. Indeed, our initial reaction to the data was to see general differences in the tone of the humble behaviors expressed in more and less hierarchical settings; in less hierarchical contexts, humble leaders were described as showing humility in playful, self-deprecating, or humorous ways, but in more hierarchical contexts, expressions of humility were always described as being serious.

Looking more closely at the data, we noticed more nuanced differences in the descriptions of humble leaders in less and more hierarchical contexts. For instance, we found that the behaviors of spotlighting follower strengths and contributions were expressed in a more "tempered" or less frequent way. Those described as humble leaders in military and industrial contexts "shared some" credit with followers, while humble leaders in the less hierarchical organizations were described as "giving all the credit" for success to followers. We observed the biggest difference in the behavior of admitting mistakes, limitations, and faults. Indeed, humble leaders in the more hierarchical contexts were described as "self-aware," but not as outwardly acknowledging limitations and mistakes very often:

He seemed to be self-aware, but he didn't articulate or share his limitations much. I think it had a lot to do with his contextual environment; it's not real cool to sit around and talk about personal stuff in the military. (interview no. 52)

Honestly, I didn't hear a lot about his failings or limitations, but I always felt able to go to him and really talk about mine. (interview no. 53)

Our understanding the differences in the enactment of humble leader behaviors across different levels of hierarchical rigidity became clearer when we applied a "temporal theoretical lens" (a timeorientation referent for each humble behavior) to the data (Ancona, Goodman, Lawrence, \& Tushman, 2001; Mitchell \& James, 2001). For example, some expressions of humble leadership seemed more past-focused (i.e., evaluating past events, such as highlighting past successes, and taking the blame for past failures); some behaviors were present-focused (i.e., behaviors in real-time interpersonal interactions, such as acknowledging when current emotions were getting the best of them, listening carefully and seeking feedback); and some humble behaviors were more future-focused (i.e., modeling tasks as a way to develop followers for future success). Viewing humble leader behaviors with this temporal theoretical lens, we found that statements from participants in military and industrial contexts suggested that leaders in these more hierarchical contexts expressed past-oriented humility (i.e., gave credit to their teams after a mission or project was accomplished, accepted blame for past failures) and future-oriented humility (i.e., modeling tasks to develop followers to succeed), but they expressed very little real-time humility (i.e., admitting weaknesses in real-time interac- 
tions). Responses suggested that this pattern might result from the emphasis on task accomplishment in these hierarchical contexts:

He seemed aware of his limitations but I don't think he saw it as necessary to discuss those with other people unless it was immediately germane. This stems from him focusing on what is necessary and needed to accomplish the task at hand. It wasn't about denial of personal limitation, just "let's focus on what we have to do.” (interview no. 31)

When on a military mission or when an industrial assembly line is running, leaders are operating in a very strong, top-down situation in which the objective is clear and they are expected to minimize deviations from that known end goal. Participants suggested that in such situations, it was less appropriate and effective for leaders to divulge areas of weakness and initiate feedback-seeking discussions with followers.

Descriptions of humble religious leaders, like those of humble military leaders, also reflected the leaders' reticence to admit mistakes and personal weaknesses to followers, but for different reasons. Because religious leaders are generally expected to be focused on helping their parishioners overcome mistakes rather than spending time discussing their own, participants reported that church leaders' admitting weaknesses and mistakes to parishioners was seen as a violation of role expectations. In addition, since religious leaders are often seen as emblems of their religious organization (i.e., symbols of its doctrine and principles; see Kreiner, Hollensbe, and Sheep [2006]), religious leaders are also considered "knowledge leaders." Unlike business leaders, who often are required to guide their groups in an uncertain, turbulent marketplace, religious leaders generally are expected to know the path that leads to a higher form of living. Thus, admitting knowledge gaps may be more acceptable in the minds of followers for a business leader than for a religious leader.

Taken together, these findings related to differences in hierarchical culture made sense to us when we realized that the likely career and reputational costs of humble behaviors in hierarchical contexts were probably much higher than they would be in nonhierarchical contexts. Military officers responsible for human lives and religious leaders responsible for human souls are held to a higher standard than office managers responsible for inventory and sales calls. But the greater risk of leader humility in hierarchical contexts may also yield a greater reward in terms of follower engagement because followers knew their humble leader would bear the brunt of ill will from the hierarchy for unit failures (i.e., what we viewed as the "martyr effect").

As an officer, I would have my higher-ranking enlisted soldiers accompany me when reporting to my superiors. I wanted them to be able to be exposed to different leadership styles than my own for their own leadership development. Sometimes they got to see me get reamed out by my superiors, which was actually a good thing. It made them want to do their jobs better. (interview no. 55)

Overall, in less hierarchical contexts it appeared that leader humility was less risky and had fewer interpersonal costs. However, because humility was more counternormative in hierarchical contexts (i.e., less common, less expected), it seemed to have a larger payoff in terms of follower engagement, trust, and loyalty.

\section{The Core Essence of Leader Humility}

Although the purpose of our study was mainly to document the observed or "lived meaning" of humble leadership, and fulfilling this purpose yielded a great deal of information regarding specific behaviors, we also were curious as to whether the statements gave any clues about the underlying essence or "way of being" captured by humble leadership. Though the data suggested to us that humble leaders possessed a generally high moral character (i.e., unselfish, other-focused), exemplified a unique kind of courage or quiet charisma, and possessed an underlying belief in personal and follower malleability, boiling our hundreds of pages of data down into one idea yield the following: Leader humility at the most basic, fundamental level appears to involve leaders catalyzing and reinforcing mutual leader-follower development by eagerly and publicly (i.e., outwardly, explicitly, transparently) engaging in the messy process of learning and growing. Even more simply put, humble leaders model how to grow to their followers. Rather than just talking about the importance of continual learning or supporting programs for followers' development and growth, humble leaders transparently exemplify how to develop by being honest about areas for improvement (i.e., acknowledging mistakes and limitations), encouraging social learning by making salient the strengths of those around them (spotlighting follower strengths), and being anxious about listening, observing, and learning by doing (modeling teachability). In our accounts, these three humble behaviors seemed to co-occur or to foster one another, ${ }^{10}$ and their synthesized

\footnotetext{
${ }^{10}$ This insight was supported by comparison with
} 
expression created the perception that the leader was obsessed with personal growth. Though humble leaders were intrinsically focused on personal growth, they also hoped their modeling would spread contagiously to followers:

My goal is to continually be growing, and having that effect trickle throughout my sphere. (interview no. 1)

This leader would tell us, "I'm so committed to growing and learning and to be a member of this team, it's important for me that you are committed to growing and learning too." (interview no. 14)

In sum, humble leaders were reported as making outwardly explicit the step-by-step process of personal development. We now describe the influence leader humility had on followers-the reported outcomes of leader humility as well as the mechanisms linking humble leader behaviors to these reported outcomes.

\section{MECHANISMS AND OUTCOMES}

In response to questions about what outcomes humble leader behaviors produced we heard general comments about increased relational satisfaction, loyalty, and trust; such comments are common responses to positive or relational approaches to leadership (see Avolio, Walumbwa, and Weber [2009] for a review). In this section, we focus instead on some of the more novel and at times counterintuitive insights revealed by our participants regarding the outcomes of humble leader behaviors and how these behaviors led to the outcomes reported (i.e., the mechanisms at work). Two emergent mechanisms reflected how followers interpreted these humble behaviors in forming ideas about workplace norms. We asked questions such as, "How did the leader's humble behaviors influence you as a follower?" and "What did these humble behaviors do to shape the work environment?" In the broadest sense, responses suggested that humble leader behaviors influenced how followers felt about both doing (i.e., method of going about the work) and becoming (i.e., attitudes toward de-

360-degree leader evaluation data from our first sample. Leaders whose direct reports rated them highly on the item "Demonstrates personal humility" were also rated very highly on the items that reflect the humble leader behaviors: "Shares credit for success" $(r=.91 ; p<.001)$; "Fosters awareness of strengths and weaknesses" $(r=.74 ; p<.001)$; "Takes time to develop and mentor his/her staff" ( $r=.70 ; p<.001)$ and "Is willing to consider ideas that are contrary to his/her own" $(r=.83$; $p<.001)$. velopment and growth). More specifically, we categorized these responses around the idea of legitimization. ${ }^{11}$ It appeared that followers viewed their leader's humble behaviors as legitimizing followers' own developmental journeys, leading to follower psychological freedom and engagement; and these humble leader behaviors were seen as legitimizing contextual uncertainty, leading to a preference for small, continuous, rather than large, discontinuous, changes and fluid organizing (i.e., ease and swiftness in transitioning to different ways of functioning). For continuity, we discuss each legitimization perception and its associated outcomes together. Illustrative quotes for each construct are presented in Table 1.

\section{Legitimizing the Developmental Journeys of Followers}

As leaders showed they were not afraid to present themselves as "in process" by being transparent about personal limitations and modeling their teachability, interviewees described feeling validated in their own developmental efforts. What was described was more than merely feeling psychologically safe in their work environment (Edmondson, 1999). In a deep sense, these humble leader behaviors influenced followers' personal ideas about "becoming," shaping, as it were, a developmental identity for the followers as members of their organization (see Dutton, Roberts, \& Bednar, 2010; Lord \& Brown, 2001). For example, one interviewee colorfully emphasized how much his humble leader's approach had influenced his own self-perceptions and his work: "This [humble leader's] mantra was 'Failure finds its grace in adjustment.' This phrase has impacted me and my work a lot. If I were to tattoo something on my body, that phrase would probably be it" (interview no. 13). Some quotes even reflected the idea that these humble leader behaviors catalyzed a developmentoriented relational identity: "12 "It is ok to be "a work in progress" here. Mutual learning and develop-

${ }^{11}$ We use Suchman's (1995) definition of legitimization as a generalized perception or assumption that certain actions are desirable, proper, or appropriate within some socially constructed system of norms, values, beliefs and definitions.

${ }^{12}$ Relational identities reflect the nature of a role relationship (e.g., leader-follower) that is shaped by the interaction between role-based identities (i.e., perceived expectations for a given role) and person-based identities (i.e., personal characteristics that influence the enactment of role-based identities [see Sluss \& Ashforth, 2007: 12]). 
ment is what my relationship with my leader is all about" (interview no. 34). Because of their leader's willingness to acknowledge their own inexperience, foibles, and shortcomings, followers believed the leader would be more understanding of follower mistakes. Leaders legitimized followers' process of development by telling followers, often with enthusiasm, that making mistakes is a normal and even a beneficial part of learning:

I tell my people that mistakes are okay, as long as you learn from them. That helps them realize that we are all going to have failures consistently and they're only going to make us stronger and catapult us further in performance and progress, and we're going to learn from them and go forward. And actually they really crave this openness because growing is an awesome process-it's exciting. (interview no. 11)

Though leader humility fostered a sense that mistakes are an acceptable part of development, it also reinforced follower accountability for acknowledging these mistakes:

In my experience as both a leader and a follower, I've found that leader humility fosters follower accountability and the desire to own up to their own faults or inexperience. And this desire for honesty and improvement creates an incredible loyalty between the follower and the leader. (interview no. 3)

Aside from the general outcomes of increased loyalty and trust already mentioned, this legitimization of followers' developmental journeys reportedly led to the outcomes of increased psychological freedom and follower engagement.

Psychological freedom. Followers' accounts reflected that the legitimization of the developmental journeys of followers resulting from humble leader behaviors produced a profound intrapersonal sense of psychological relief and reduced evaluation apprehension. Followers of humble leaders felt "freed" to risk being transparent about their own developmental process and show others, without self-denigration, how they were working to bridge the gap between their real and ideal selves (Higgins, 1989). Humble leaders' admissions of limitations and mistakes were described as showing followers that leaders were interested in follower development and not just in their performance, which freed followers both from the psychological burden of hiding their inexperience and mistakes and from the burden of maintaining and defending an unrealistically high self-image. "It [the leader's humility] let down the tension inside. It let down any sense of having to prove yourself. It gave me permission to be honest about my shortcomings" (interview no. 30). Some cited a connection be- tween this psychological freedom and improved performance:

Leaders who are humble foster a kind of comfort [in followers].... When you have that in followers, you get better results. (interview no. 9)

In addition, evidence from self-reports suggested that behaving humbly had its own psychological benefits for leaders as well. For example, when asked about the potential benefits of humility, one leader said: "Freedom, I mean absolute freedom. To enjoy yourself and enjoy others around you and see them for who they are. It takes a burden off your shoulders." (interview no. 8). "Behaving humbly as a leader is a good use of power. I can go to bed with peace of mind" (interview no. 52). Another leader told us: "Humility helps me be real. I just feel like humility lets me live the life that I desire as opposed to having the psychological hurdles getting in my way" (interview no. 14). As leaders and followers experience more freedom from "psychological hurdles" as a result of humble leader behaviors, more psychological and emotional resources are freed to expend toward more productive ends. In other words, this psychological relief or comfort may lead to "better results" because followers are freed from the cognitive burdens associated with the fear of making mistakes or showing inexperience and so have more cognitive resources for in-depth (rather than heuristical) processing (Baumeister \& Bushman, 2008; Fiske \& Taylor, 1984) and creativity (Edmondson, 2004).

Follower engagement. Our participants also told us that followers often responded to humble leader behaviors with increased job engagement and motivation to do their work. The legitimization of personal development appeared to enhance followers' intrinsic motivation to learn and master job tasks and shift followers from a goal of meeting external performance standards (i.e., praise from the boss, getting a bonus) to one of trying to meet internal performance standards (cf. Dweck, 1999). At the onset of this study, we wondered whether humble leader behaviors might cause followers to relax their focus on accomplishment. However, many followers of humble leaders reported enhanced motivation as due to leader humility:

I actually enjoy working late and going above and beyond the call of duty when [my humble leader] genuinely asks for help about something or admits they are confused about an issue. My [nonhumble leader] thought he had all the answers and so it seemed like no matter what I did it wasn't good enough or the way he liked it done. Part of the problem was that he expected me to read his mind, 
so it was safer just to do the bare minimum. (interview no. 47)

Participants reported that a small humble leader behavior stimulus (e.g., asking for advice) could produce a tremendous amount of follower work effort, whereas a very strong stimulus from a nonhumble leader (e.g., yelling at followers to do everything their way) was demotivating to followers. For example:

When my leader shows humility and is open to what others have to say it creates an environment of energy. I come to the meetings prepared. Rather than stepping in the room and saying "Okay, he's going to set the agenda and we are going to sit here and listen for an hour," it's more interactive, we feel like we have more impact. Changes the whole thing up. (interview no. 14)

My previous regional president was kind of like, "I know everything. I'm the boss" and if you didn't agree with him you were disagreeing and he took it personal. . . . It got to a point where if I didn't have the same opinion, I didn't say anything at all. (interview no. 10)

Those described as nonhumble leaders effectively shut down the discretionary contributions of their followers (e.g., followers psychologically detached from the nonhumble leader and did the bare minimum [interview nos. 10 and 52]), whereas humble leader behaviors reportedly unlocked and amplified follower intrinsic motivation. The interview responses also suggested that humble leaders' willingness to model follower tasks (as part of the modeling teachability behavior) helped enhance the perceived meaningfulness and importance of the tasks to followers, which are also important factors for fostering job engagement (Kahn, 1990).

Humble leaders were also described as adept at "parlaying employees into the right places" (interview no. 31) and capitalizing on the unique aptitudes and skills of followers: "Knowing my employees allows me to play to their strengths and procure for them new and different duties that create a passion that excites them about what they do" (interview no. 6). Not only were humble leaders more "hands off"- -their followers were also more "hands on" and even were ready to take the leadership role when necessary:

I had a recent situation in our branch where I told the district manager, "Please take the lead. I'm getting too emotionally reactive here. I am not fit to be dealing with this right now." She took the responsibility and she was wonderful. She stepped up and took care of it. (interview no. 10)

When hard-nosed leaders "crack" in combat, followers just sit back and think the leader is weak. How- ever when humble leaders "crack" in theater, their followers usually step up and shoulder more of the leader role. (interview no. 55)

In sum, all humble leader behaviors led followers to feel that personal development was a legitimate workplace goal, which increased the followers' intrinsic motivation to be engaged in their jobs.

\section{Legitimizing Uncertainty}

In seeking to learn how and why the humble leader behaviors led to the outcomes described, we noticed an important follower perception that we have labeled "legitimizing uncertainty." Most of our interviewees, even those in bureaucratic contexts such as the military and industrial organizations, reported a work context of uncertainty, turbulence, and dynamic change. The humble leaders' acknowledgment of their own uncertainty helped to validate followers' uncertainty and encouraged an environment of experimentation and learning dialogue. For instance, one interviewee said, "We as a group never felt uncomfortable saying to this [humble] leader, “This doesn't make sense" (interview no. 53). In contrast, nonhumble leaders, who were described as pretending to "know it all," were perceived as disconnected from the dynamic context in which organization members operated, and followers said they were reluctant to acknowledge what they did not understand or even ask clarifying questions.

Interviewees suggested that leaders set the tone of adopting a posture of certainty or instead of acknowledging uncertainty. When leaders had a "certainty posture," followers felt they should bottle up their uncertainty until they could present a well-polished, more certain plan: "You'd better have all your ducks in a row. Every word you say would need to be measured and proven" (interview no. 53). Instead of being paralyzed by uncertainty and making mistakes, humble leaders enabled and encouraged followers to vocalize their uncertainties and doubts and to feel their way forward by experimenting through trial and error. Humble leaders reinforced the value of experimenting and staying in motion by encouraging followers to "just make the decision and go with it; if it is wrong we'll learn from it" (interview no. 55). According to those we interviewed, this legitimization of uncertainty and trial-and-error learning led to a preference for continuous small changes over discrete large changes and greater fluidity in organizing.

Preference for continuous small changes. On a unit level, the frequency and magnitude of change were mentioned as being influenced by humble 
leader behaviors and the legitimization of uncertainty. Units led by humble leaders functioned in a way that favored small, continuous changes rather than large, infrequent changes. Participants reported that humble leader behaviors enabled teams to adapt to their environment better by constantly updating and matching team member strengths with changing environmental demands. The behaviors of modeling teachability and admitting ignorance were described as especially important for helping followers not interpret uncertainty as a threat (see Staw, Sandelands, \& Dutton, 1981), but as a common and valid assessment of their environment. This legitimization of uncertainty fostered acceptance of unpredictability, openness to new information, and more trial-and-error experimenting. Thus, units led by humble leaders were in "learning mode" much of the time, favored frequent course reevaluation and updating (that is, "making small, day-to-day changes" ([interview no. 34]), had a "line upon line, fix little things here and there" approach (interview no. 18), and "favored incremental changes" (interview no. 50). Although legitimizing uncertainty, these leaders fostered a culture that recognized that ongoing information should be used to evaluate the accuracy of initial decisions. Thus, they questioned initial decisions and made constant adjustments. "Humble leaders improve the effectiveness of the decision-making process and speed the process of effective adaptation" (interview no. 7). Humble leaders were less likely to escalate commitment to failed courses of action (e.g., Staw, 1981) because they were more open to feedback and less likely to make and adhere to decisions for purposes of selfvalidation or self-enhancement. For instance: "Someone who has humility would ... be better able to listen to peers and other resources so they don't keep going down paths that are nonproductive" (interview no. 29).

Humble leaders also helped followers value staying in motion and creating solutions that were "good enough for now" rather than permanent and perfect. Thus, humble leaders were reported as valuing moving in the "right direction" rather than making the "right decision." Humble leaders also fostered more of an "'if it isn't broken, don't fix it' mentality" (interview no. 50), wherein they were more likely to build on current foundations rather than start fresh to build something that was all their own creation (i.e., "[They are] willing to stand on the shoulders of those who had gone before" [interview no. 31]). The small, continuous change approach humble leaders fostered seems to contrast with the bold, all-or-nothing approach of narcissistic leaders that is aimed at drawing attention to themselves, is often vehemently defended, and results in either a big win or a big loss (Chatterjee \& Hambrick, 2007).

Fluidity in organizing. The units in which humble leaders led were also described as being more able to make swift or fluid transitions between different types of organizing (i.e., top-down versus bottom-up) in response to changing situational demands. Because humble leaders legitimized uncertainty, follower responses reflected greater understanding of the need to adapt to different environmental challenges and reported being more receptive when the humble leader initiated changes in a unit's way of functioning. Specifically, though humble leaders' units typically functioned in a bottom-up manner, their followers more quickly "bought-in" (interview no. 8) and "jumped on board" (interview no. 34) when the leaders felt a situation called for their teams to function in a more top-down fashion. For instance, one interviewee described how the firm needed to make a "momentary" transition from their "collaborative and democratic" culture to respond effectively to immediate challenges: "Things are going to be coming down the pipeline in a more edict-military type way, because the situation that we're in calls for that. We [the followers] understand that this is not a total departure from our culture, but it is a momentary departure from our culture" (interview no. 2). Followers appeared to be more receptive and "aligned" (interview no. 11) to these changes because followers and leaders freely acknowledged the uncertainty they were facing. Leaders and followers agreed that sometimes uncertainty demands a top-down mode of organizing, such as when a unit is facing a significant, urgent threat.

Units with leaders described as nonhumble, in contrast, were reported as being much less fluid in organizing their structure. When such a leader saw the need to try a more bottom-up approach, followers were described as more suspicious and reticent to participate for fear of saying something out of line with the leader's thinking: "From my experience, when a command-and-control leader decides to try a humble, team approach, at first followers are like, 'What's the catch?' It takes a while to change the dynamic. Followers won't buy into it immediately. It takes time to believe it" (interview no. 8). "Because of my previous experiences [with a non-humble leader], it took me a while to open up and really share what I was thinking" (interview no. 6).

In relation to fluidity in organizing, from leaders' own perspectives (our self-reported accounts), humility enabled them to "get out of autopilot mode" (interview no. 12) and recognize when their lead- 
ership approach was not working and a unit needed to function in a different manner. Participants reported that leader humility played a selfregulatory function, helping leaders more effectively adjust their leadership styles or approaches to initiate different types of unit functioning.

I think it is critical to have the ability to reflect inward and recognize when you need to try a different approach. . . . Humility entails opening your eyes in seeing that in leadership you can't just treat people like you want to be treated, or the way you operate. You have to realize what their needs are and lead according to that. (interview no. 53)

Many leaders said humility spurred them to temper initial adherence to traditional, top-down approaches to leadership, enabling them to see when they had been too rigid, too forceful, or "ascendant" (interview nos. 8, 14, 15, 16, and 28). But we were surprised to hear that sometimes humility moved leaders in the other direction, making them more tough, forceful, and top-down when they saw it as necessary. For example, one leader said: "It took humility to realize that my being too relational with followers was in an effort to fulfill my own needs, not theirs. It was not serving them or the business well. I saw that I needed to adjust my leadershipstyle back toward the more firm, command-andcontrol approach" (interview no. 7). In short, leader humility was described as enabling leaders to acknowledge when their leadership was out of balance and temper or regulate it in either direction ("harder" or "softer"). Thus, we found that leader humility does not necessarily mean a leader will have difficulty making hard decisions and being forceful when necessary, but rather that he or she will be more mindful in evaluating whether an approach is appropriate to the situation. Overall, leader humility helped leaders recognize when they needed to change the way their units functioned, and followers of humble leaders were more receptive to these changes in organizing.

\section{DISCUSSION}

In response to recent calls for a deeper examination of bottom-up leadership (Uhl-Bien, 2006; Weick, 2001), our findings highlight the behaviors, mechanisms, contingencies, and outcomes of humble leadership. Though many have speculated about what humble leadership is and why it is important, this is the first study that we are aware of that documents the lived meaning and the enactment of humble leadership. Through an inductive approach, we identified the behaviors that organization members in a variety of contexts view as humble, as well as the outcomes and the boundary conditions for the effectiveness of such behaviors. Leadership research and theory have been criticized as being too segmented, and calls have been made for more integration of findings from different leadership approaches (i.e., integrating leader traits, leader behaviors, follower cognitions, situational/contextual factors [see Yukl, 2010: 491]). We examined and built this theory of humble leadership with these calls in mind, as our theory touches on leader behaviors, leader underlying beliefs, follower cognitions, contextual and situational factors, and outcomes for both leaders and followers. Though uncovering the lived meaning of humble leadership in organizations is important, the main contribution of this study is our process model describing in detail exactly how humble leader behaviors legitimize follower development and follower uncertainty. These follower legitimization cognitions provide an explanatory mechanism that is often lacking in existing leadership theory (Yukl, 2010: 496). In response to another major criticism of leadership theory-that it is too decontextualized (Yukl, 2010: 492)—we structured our study to illuminate boundary conditions, situational constraints, and contextual factors that influence the appropriateness and effectiveness of humble leadership by sampling a broad array of organizational types and leadership levels. The contingencies of leader perceived competence, sincerity, situational level of threat and time pressure, organizational learning culture, hierarchical rigidity, and level of threat and time pressure are important contributions to the humble leadership literature, which may also have important application to other bottom-up leadership theories. Below, we discuss the theoretical implications of this study for the field of leadership, leader and follower development, follower engagement, emergent change, and transitioning between top-down and bottom-up approaches to organizing, as well as the uniqueness of our theory of leader humility among other bottom-up leadership approaches.

\section{Theoretical Implications}

Both in theory and in practice, leaders have long been depicted as demigods, heroes, and superhuman saviors (Murrell, 1997; Yukl, 1998). Our theory and findings provide a substantive theoretical counterweight to such models by identifying the positive developmental influence leaders can have on followers by modeling how to be effectively human rather than superhuman. Certainly topdown heroic leadership may be useful in some contexts, and our results identify extreme situa- 
tions in which top-down approaches should be preferred over bottom-up approaches. However, our findings suggest that bottom-up leadership approaches are more wholly appropriate and greatly needed in today's knowledge-driven economy (Lichtenstein, Uhl-Bien, Marion, Seers, Orton, \& Schreiber, 2006). The humble leader behaviors we identified (e.g., acknowledging mistakes, spotlighting follower strengths, modeling teachability) and the mechanisms (e.g., legitimization of uncertainty and personal development) were often described in our interviews as directly challenging the more popular top-down conceptions of leadership.

Although some common leadership pundits and approaches appear to legitimize pretending ("fake it till you make it," "show no fear," "power posing," and "macho posturing” [Weick, 2001; Carney, Cuddy, \& Yap, 2010]), humble leaders legitimize the actual process of becoming. In other words, the core impact of leader humility on followers appears to be followers' constructive and adaptive responses to their own inexperience, gaps in development, and mistakes. By helping to reduce follower anxiety and evaluation apprehension during the process of development, humble leaders help free up followers' psychological resources to be used toward more productive ends. Such a finding has important implications for the leadership development literature, helping to form a bridge between leader development (describing the growth of the intrapersonal and other skills of those in formal leadership positions) and a context of leadership development (a work environment in which both leaders and followers are able to develop leadership skills and engage in self-leadership regardless of position [Day, 2000]). Leader humility appears to be a specific and effective way to foster this context of leadership development through the process of rendering the intrapersonal (internal) states of leaders interpersonal, making self-awareness, emotional regulation, social learning, and teachability explicit and salient in the process of leaderfollower interactions. In addition, leader humility may have important implications for fostering "developmental readiness" (a topic leadership scholars have pinpointed as critically needed in future leadership research [Avolio et al., 2009]) between both leaders and followers, as the behaviors of leader humility appear to catalyze a type of interaction in which leader and follower developmental activities are mutually reinforced.

In addition, the difference between legitimizing pretending versus actual becoming also appears to have important implications for the evolution of leader-follower relationships. As our data suggest, followers of a humble leader are less likely to ex- perience disillusionment-and the associated mistrust, disloyalty, contempt, and dissatisfactionwith their leader over time because the leader never tried to create any illusions to begin with. Thus, the development of a humble leader-follower dyadic relationship may follow a steadier, upward path, marked by increasing trust, mutual respect, and loyalty, rather than the suggested leader-follower relational stages of honeymoon, disillusionment, and (hopefully) reconciliation (Agashae \& Bratton, 2001). Leader humility may lead to more stabile leader-follower relations because humble leaders effectively foster identification (i.e., through conveying being in a common predicament with followers with regard to uncertainty and the need for constant development) without fostering overdependence (Kark, Shamir, \& Chen, 2003) or leader idealization (in which followers "elevate leaders to heights from which they can rarely fail [to] disappoint" [Gabriel, 1997: 317]).

Our findings also contribute to the growing literature on job engagement, which is not yet definitive about what specific leadership approaches best foster follower engagement. ${ }^{13}$ Rather than seeking to engage followers through charisma, energy, idealism, and stimulation, on which the empirical evidence has been inconsistent (see Dvir, Eden, Avolio, \& Shamir, 2002), our study suggests that the "quieter" approaches of modeling teachability and validating follower developmental processes and experimentation are important for fostering intrinsically engaged employees. Our results suggest that leader humility may help reduce some of the obstacles that inhibit followers from feeling engaged in their work (Schaufeli \& Bakker, 2004). Specifically, our data suggest that humble leader behaviors go beyond fostering followers' feeling psychologically safe and supported by their leader (Bakker, 2005; Kahn, 1990) to help affirm followers' process of development, foster a more adaptive attitude toward mistakes and trial-and-error learning, and free more of followers' psychological resources (i.e., psychological freedom) to dedicate to workrelated tasks. In addition, humble leaders' modeling of follower tasks, large or menial, helped to ennoble or elevate the tasks in the minds of followers, making it more likely that they will not see the tasks as merely unimportant "grunt" work, but as intrinsically worthwhile. Thus, this study provides important elaborative insight revealing a constella-

\footnotetext{
${ }^{13}$ Little is known about what leadership behaviors or approaches best foster job engagement beyond the general ideas of supportiveness (Bakker, 2005) and managerial effectiveness (Mauno, Kinnunen, \& Ruokolainen, 2007).
} 
tion of specific leader behaviors that influence follower cognitions, which in turn foster a heightened sense of job engagement. Recent empirical study supports this connection between leader humility and follower engagement (Owens et al., 2012).

Aside from the individual-level implications of our study, our model of bottom-up, humble leadership also adds important insight into the literature of bottom-up change in organizational units (Burnes, 2004; Cummings \& Worley, 2001; Dawson, 1994; Weick, 2000). Though some advocate more top-down strategic change approaches (Conger, 2000) others argue the need for organizations to learn to "grow strategy from below" (Brown \& Eisenhardt, 1998; Sayles, 1993), seek bottom-up "small wins" (Kouzes \& Posner, 1997), and engage in "opportunistic experimentation" at lower organizational levels (Collins \& Porras, 1994). Advocates of emergent change (Burnes, 2004) argue the importance of organizations being willing to live on the "edge of chaos" to achieve the level of flexibility and adaptability required for continuous transformation. Our findings contribute to this research by identifying the previously unspecified leadership behaviors that facilitate this type of change or growth. ${ }^{14}$ We suggest that the inertia that keeps organizations from adapting in pace with a changing environment may be in large part due to leader rigidity (rather than teachability) in decision making; creating overdependence on leader knowledge and expertise (rather than acknowledging and encouraging the strengths and contributions of followers); and leaders' overconfidence in their own ability to anticipate the future (rather than admitting limitations and knowledge gaps). Leaders admitting limitations, modeling teachability, and legitimizing uncertainty may provide the "disequilibrium" or "shock to the system" needed for an organization to stay in a continuous change state and foster the unit reflexivity (reflection, planning, and adaptation) needed for continual unit learning (Swift \& West, 1998). As matching resources with evolving opportunities, constraints, and demands is a key skill in emergent change (Hayes, 2002: 37), humble leadership appears to help foster this matching, because the humble leader behavior of spotlighting follower strengths may produce a consensual awareness of what human resources a team has to allocate to meet evolving demands. In sum, we believe that the behaviors of humble leadership help give more clarity to the specific leadership

\footnotetext{
${ }^{14}$ One of the few specific examples of advocacy of leader behaviors to facilitate bottom-up growth is Jenner (1998), who proposes decision delegation to followers.
}

approaches that facilitate emergent change in organizations.

In light of theory suggesting that top-down and bottom-up approaches be integrated for optimal change effectiveness (Conger, 2000; Dunphy, 2000), our study contributes an important insight with regard to an asymmetrical effect in transitioning between top-down and bottom-up organizing styles. Transitioning from a humble, bottom-up to a top-down functional approach was described as much easier (i.e., the transition was quicker, the followers were more responsive) than transitioning from a top-down to a bottom-up approach. This difference in going from top-down to bottom-up organizing versus from bottom-up to top-down organizing appears to happen because humble leaderfollower interactions are more complex; there is more blurring of role boundaries and more uncertainty in role expectations, and dynamic, mutual influence is present. Top-down leader-follower relationships are generally less complex, as leaders give orders and followers carry them out. For leaders whose default position is top-down leadership, it is more difficult to transition to the bottom-up, humble leadership approach because it requires the melting of heretofore rigid role relationships, and followers have not been developed to take part in the leadership process. Thus, humble leaders have a much easier and quicker time transitioning to a lower-order relational mode (i.e., less complex, top-down mode) than top-down leaders who try to transition to a bottom-up mode.

Our findings also contribute to research on leader behaviors that are thought to promote flexibility in rigid organizational bureaucracies-that is, the literatures regarding "dynamic delegation," "constrained improvisation," and "authority migration" (Bechky, 2006; Bigley \& Roberts, 2001; Klein, Ziegert, Knight, \& Xiao, 2006). Each of these leader behaviors involves leaders relying on followers for direction in bureaucratic organizations. Our results support what we perceive to be the main point of these literatures: that bottom-up leader behaviors are useful in hierarchies, even if they occur less often. However our model expands and enriches this finding by revealing some boundary conditions for the effectiveness of bottom-up leader behaviors (i.e., situations of extreme threat and time pressure, presence of a learning culture, perceptions of leader competence and sincerity). Furthermore, this research also answers calls to understand more fully the mechanisms behind team learning and reflexivity (Swift \& West, 1998). Though recent research has helped to illuminate some structural methods for facilitating team learning (see Vashdi, Bamberger, Erez, \& Weis-Meilik, 2007), our research 


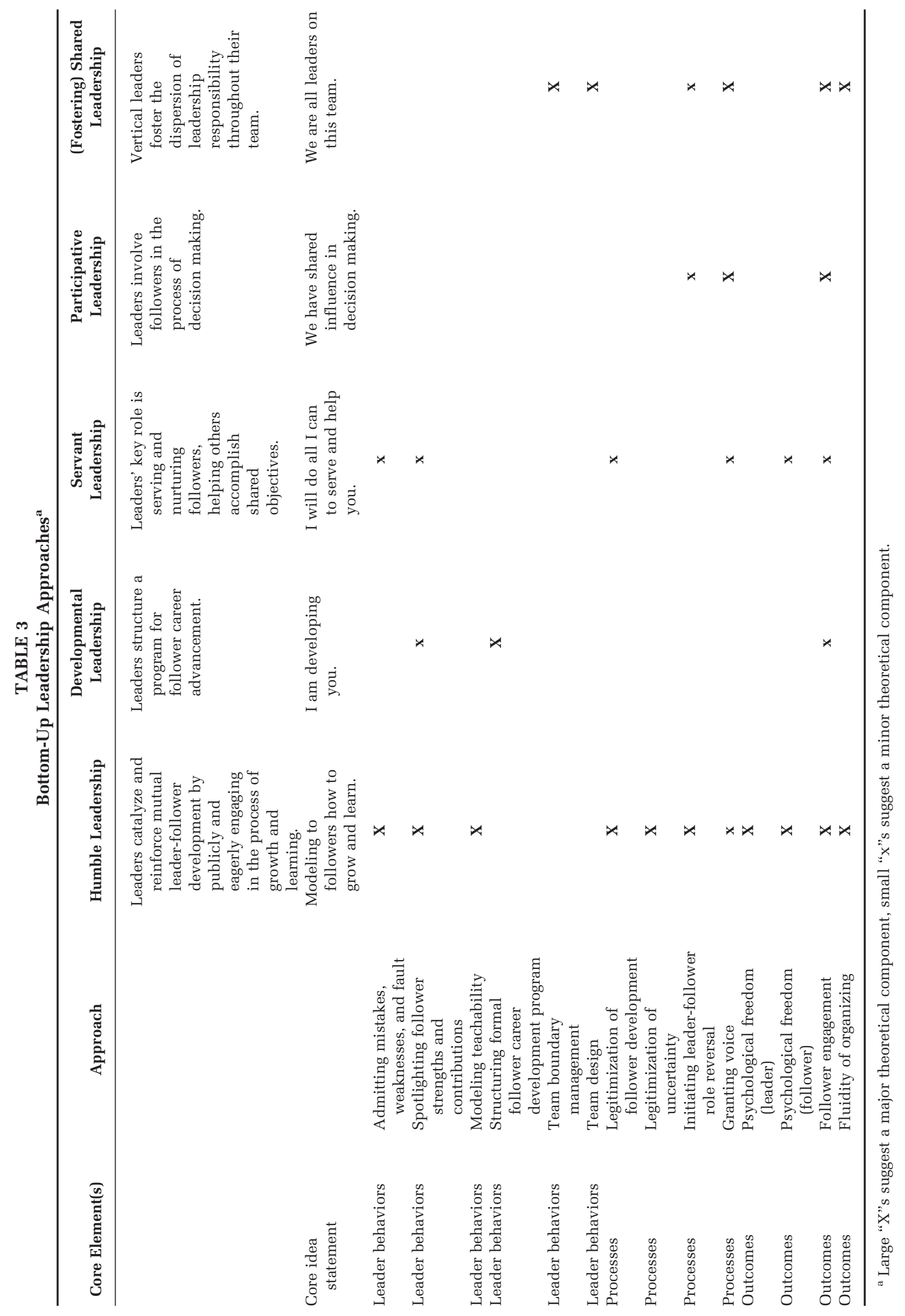


uncovers specific leader behaviors that influence the perceptions of followers en route to establishing a unit culture conducive to learning and adaptation.

\section{Construct Differentiation}

Looking over the above implications of this study, we feel that to clearly identify the contributions of this work, it is critical to differentiate how our emerging theory of humble leadership is unique among existing and related bottom-up leadership theories. Though an extensive review of all closely related leadership theories is not possible here, in Table 3 we summarize the elements of our humble leadership model and compare how each of these elements is related to what we view as the most closely related leadership perspectives: developmental, servant, participative, and shared leadership. ${ }^{15}$

By definition, developmental leaders are those who "advise staff on their careers, carefully observe and record followers' progress and encourage staff to attend technical courses" (Rafferty \& Griffin, 2006: 39). Developmental leadership is tied to the mentoring literature, though it focuses on mentoring's career-oriented rather than psychosocial aspects (Kram, 1985). Humble leadership, in contrast, appears to capture a much more informal and mutual developmental relationship with followers. It focuses on the influence of leader behaviors on follower cognitions rather than on structured programs for follower career development.

Servant leaders view themselves as servants first and leaders second, and "view the development of followers as an end, in and of itself, not merely a means to reach the leader's or the organization's goals" (Ehrhart, 2004: 69). Though there are several similarities between our humble leadership theory and servant leader theory, a general focus on development being the most obvious, there are also core differences. These, in our view, are (1) humble leadership's focus on modeling the process of becoming for followers, versus servant leadership's focus on modeling serving others, and (2) the legitimization of uncertainty under humble leadership. Humble leadership also implies leader and follower psychological freedom, fluidity of organizing, fostering a tendency toward continuous, small

\footnotetext{
15 To check our view of how humble leadership is unique, we sent this section and Table 3 to prominent scholars who have published articles in these leadership areas and made adjustments according to the feedback received.
}

changes, and initiating leader-follower role reversals, processes that are not a major emphasis in the servant leadership literature.

At its core, participative leadership involves "joint decision-making or at least shared influence in decision-making by a superior and his or her employees" (Somech, 2003: 1003). Although participative leadership describes a decision-making approach or structure, it does not focus on specific interpersonal behaviors that reflect modeling development and how these behaviors influence follower (and leader) cognitions and attitudes. Similarly, shared leadership-often used interchangeably with distributed leadership, team leadership, and democratic leadership-occurs when "all members of the team are fully engaged in the leadership of the team" and is most germane to the contexts that entail interdependence and complexity (Pearce, 2004: 48). We view the humble leadership of a vertical leader as potentially antecedent to a norm of shared leadership in a team, yet examining shared leadership and what type of leader approach fosters it says little about the specific humble leader behaviors and the process of legitimizing development and uncertainty. Instead, the focus of vertical leaders seeking to foster shared leadership is on issues of team boundary management and team design.

Overall, though all the closely related leadership perspectives have some focus on follower development-structuring career advancement goals (developmental leadership), sharing decision-making power and leadership influence throughout a group (participative and shared leadership), and viewing follower development as an end in itself (servant leadership)—humble leadership is unique because of its major focus on leaders' transparency about their own developmental processes. Though there is some conceptual overlap between leader humility behaviors, processes, and outcomes and these other related constructs (as reflected in Table 3), there are also important novelty and uniqueness that are not captured by the core elements of these existing bottom-up constructs, such as modeling teachability, legitimization of follower development and uncertainty, initiation of leader-follower role reversals, continuous small-scale adaptation, fluidity of organizing, and leader-follower psychological freedom.

\section{Limitations and Future Research}

Because of our retrospective study design, the incidents reported to us may suffer from participant self-enhancement or "sensemaking" biases. We sought to minimize problems associated with a 
retrospective design by asking participants to talk about someone else and by using a courtroom style of questioning (Eisenhardt, 1989; Eisenhardt \& Graebner, 2007). Furthermore, many of our participants reported unflattering aspects of themselves, indicating that rosy retrospective bias may not be a major cause for concern (Mitchell \& Thompson, 1994). Though we feel our method of learning about the lived meaning or mental models of humble leadership was appropriate for our goals, we recommend that future research directly explore to what degree these mental models of humble leader behaviors and their connection to the outcomes and moderators that we have identified bear out in subsequent behavioral observation studies.

Our model also does not speak directly to the enablers, sources, and antecedents of leader humility. Ideas put forth about what precipitates or fosters humility in leadership include low narcissism and Machiavellianism and moderate self-esteem (Morris et al., 2005); a collective orientation (Nielsen et al., 2010); and undergoing traumatic events or certain aspects of a religious upbringing (Collins, 2001a); however, nothing yet has been substantiated. Future research should explore the potential personal and contextual antecedents of leader humility to gain insight about how it might be selected for or fostered in an organizational context. Specific to our leader competence contingency, status characteristics theory (Berger, Fisek, Norman, \& Zelditch, 1977) supports the idea that factors in addition to age and gender, such as a leader's ethnicity, race, and education level, may also influence the effectiveness of humble leader behaviors. Future research should explore how other demographic differences besides the ones we identified may shape when a leader decides to behave humbly and how humble leader behaviors are interpreted. Since age and gender attribution biases are more operative in ambiguous contexts (see Hekman, Aquino, Owens, Mitchell, Schilpzand, and Leavitt [2010] for a review), we documented evidence that external leadership signals of authority found in more hierarchical organizations (i.e., military chevrons, religious regalia) may reduce the tendency for followers to view humble behaviors of young and female leaders as weakness. Future research should explore the possibility that the presence of external signs of authority mitigates the stereotypical biases against female (Eagly, 2007; Eagly \& Karau, 2002; Ragins \& Winkel, 2008) and minority (Rosette, Leonardelli, \& Phillips, 2008) leaders. Lastly, as we identified beliefs about personal and others' malleability as part of the roots of humble leadership, we also recommend future research examine how leader humility may be asso- ciated with or driven by incremental implicit person theories (Dweck, 1991; Dweck, Chiu, \& Hong, 1995)

Future research should also examine how humble leader behaviors interact with other leadership approaches. As our study suggests, humility appears to play a self-regulatory function that prevents an individual's leadership approach from going to extremes. It may be that humility enables a leader to temper visionary, charismatic, or transformational approaches to influencing others so as to prevent the dark side of such approaches (i.e., overidentification [Kark et al., 2003]; "pseudo-" transformational leadership [Morris et al., 2005]; or abuse of power [Conger, 1990]). Future research should examine, for instance, whether and in what contexts humble transformational leaders are more effective than less humble ones.

Because all of those we interviewed were from organizations in North America, we recommend future research also examine the relationships we uncovered in other cultural contexts. Given our findings related to hierarchical culture, it may be particularly interesting to examine leader humility in countries with generalized differences in the dimensions of uncertainty tolerance, collectivism/ individualism, and masculinity/femininity (Hofstede \& Hofstede, 2005). In addition, future research should also examine further how leadership level influences the effectiveness and appropriateness of leader humility. Though we report some differences in the function of humble leader behaviors enacted by higher- and lower-level leaders (i.e., higher-level leaders setting the tone of a learning culture that makes humble behaviors of lower-level leaders more acceptable), more examination is needed to understand how leader level differences in decision latitude, task regimentation, and external signals of authority influence the interpretation and effectiveness of humble leader behaviors.

\section{Conclusion}

Humility in leadership is a topic that becomes more relevant as markets continue to globalize and firms grow more complex and diverse. In such environments, it becomes less feasible for any single leader to know everything (Senge, 1990). When summarizing the literature on why leaders fail, Burke noted that it is "not what [leaders] know or how bright they are that leads to success or failure; [rather] how well they work with others, and how well they understand themselves" (2006: 94). We suggest that to effectively lead their firms amidst growing market complexity, leaders increasingly must be able to humbly show their followers how 
to grow by admitting what they do not know, modeling teachability, and acknowledging the unique skills, knowledge, and contributions of those around them. Our hope is that the inductive insights presented in this study spur further interest in exploring humility in the context of leadership.

\section{REFERENCES}

Agashae, Z., \& Bratton, J. 2001. Leader-follower dynamics: Developing a learning environment. Journal of Workplace Learning, 13(3): 9-102.

Ancona, D. G., Goodman, P. S., Lawrence, B., \& Tushman, M. L. 2001. Time: A new research lens. Academy of Management Review, 26: 645-663.

Armstrong, S. J., Allinson, C. W., \& Hayes, J. 2002. Formal mentoring systems: An examination of the effects of mentor/protégé cognitive styles on the mentoring process. Journal of Management Studies, 39: 1111-1137.

Avolio, B. J., \& Gardner, W. L. 2005. Authentic leadership development: Getting to the root of positive forms of leadership. Leadership Quarterly, 16: 315-338.

Avolio, B. J., Walumbwa, F. O., \& Weber, T. J. 2009. Leadership: Current theories, research, and future directions. In D. L. Schacter \& S. E. Taylor (Eds.), Annual review of psychology, vol. 60: 421-449. Palo Alto, CA. Annual Reviews.

Bakker, B. 2005. Flow among music teachers and their students: The crossover of peak experiences. Journal of Vocational Behavior, 66: 26-44.

Ballinger, G. A., \& Schoorman, F. D. 2007. Individual reactions to leadership succession in workgroups. Academy of Management Review, 32: 118-136.

Bass, B. M. 1990. Bass and Stogdill's handbook of leadership: Theory, research and managerial applications (3rd ed.). New York: Free Press.

Bass, B. M. 1997. Does the transactional/transformational leadership transcend organizational and national boundaries? American Psychologist, 52: 130-139.

Bass, B. M., \& Avolio, B. J. 1990. Multifactor leadership questionnaire. Palo Alto, CA: Consulting Psychologist Press.

Baumeister, R. F., \& Bushman, B. J. 2010. Social psychology and human nature (2nd ed.). Belmont, CA: Wadsworth.

Bechky, B. A. 2006. Talking about machines, thick description, and knowledge work. Organization Studies, 27: 1757-1768.

Berger, J., Fisek, M. H., Norman, R. Z., \& Zelditch, M., Jr.. 1977. Status characteristics and social interaction: An expectation states approach. New York: Elsevier.
Biernat, M., \& Fuegen, K. 2001. Shifting standards and the evaluation of competence: Complexity in genderbased judgment and decision making. Journal of Social Issues, 57: 707-724.

Bigley, G. A., \& Roberts, K. H. 2001. Structuring temporary systems for high reliability. Academy of Management Journal, 44: 1281-1300.

Blake, R., \& Mouton, J. 1964. The managerial grid: The key to leadership excellence. Houston: Gulf Publishing.

Boje, D. M., Roslie, G. A., Durant, R. A., \& Luhman, J. T. 2004. Enron spectacles: A critical dramaturgical analysis. Organization Studies, 25: 751-774.

Bono, J. E., \& Judge, T. A. 2004. Personality and transformational and transactional leadership: A metaanalysis. Journal of Applied Psychology, 89: 901910.

Boyatzis, R. 1998. Transforming qualitative information: Thematic analysis and code development. Thousand Oaks, CA: Sage.

Bright, D. S., Cameron, K. S., \& Caza, A. 2006. The amplifying and buffering effects of virtuousness in downsized organizations. Journal of Business Ethics, 64: 249-269.

Brinkerhoff, D. B., White, L. K., Ortega, S. T., \& Weitz, R. 2007. Essentials of sociology (7th ed.). Belmont, CA: Thompson and Wadsworth.

Brown, S. L., \& Eisenhardt, K. M. 1997. The art of continuous change: Linking complexity theory and time-paced evolution in relentlessly shifting organizations. Administrative Science Quarterly, 42: $1-34$.

Bryman, A. 2004. Qualitative research on leadership: A critical but appreciative view. Leadership Quarterly, 15: 729-769.

Burke, R. J. 2006. Why leaders fail: Exploring the darkside. International Journal of Manpower, 27(1): 91-100.

Burnes, B. 2004. Emergent change and planned changeCompetitors or allies? The case of XYZ construction. International Journal of Operations \& Production Management, 24: 886-902.

Burns, T., \& Stalker, G. M. 1961. The management of innovation. London: Tavistock.

Butler, P. D., Swift, M., Kothari, S., Nazeeri-Simmons, I., Friel, C. M., Longaker, M. T., \& Britt, L. D. 2011. Integrating cultural competency and humility training into clinical clerkships: Surgery as a model. Journal of Surgical Education, 68: 222-230.

Cameron, K. S., \& Caza, A. 2004. Contributions to the discipline of positive organizational scholarship. American Behavioral Scientist, 47: 731-739. 
Cameron, K. S., Dutton, J. E., \& Quinn, R. E. 2003. Positive organizational scholarship: Foundations of a new discipline. San Francisco: Berrett-Koehler.

Cameron, K. S., \& Quinn, R. E. 2005. Diagnosing and changing organizational culture. San Francisco: Jossey-Bass.

Carlyle, T. 1869. On heroes, hero-worship, and the heroic in history. London: Chapman and Hall.

Carney, D., Cuddy, A., \& Yap, A. 2010. Power posing: Brief nonverbal displays affect neuroendocrine levels and risk tolerance. Psychological Science, 10: 1363-1368.

Chatterjee, A., \& Hambrick, D. C. 2007. It's all about me: Narcissistic CEOs and their effects on company strategy and performance. Administrative Science Quarterly, 52: 351-386.

Cohen, J. 1960. A coefficient of agreement for nominal scales. Educational Psychological Measurement, 20: $37-46$.

Collins, J. C., \& Porras, J. I. 1994. Built to last. New York: HarperCollins.

Collins, J. 2001a. Good to great. New York: HarperCollins.

Collins, J. 2001b. Level 5 leadership: The triumph of humility and fierce resolve. Harvard Business Review, 79(1): 67-76.

Confucius. 2006. The analects. Minneapolis: Filiquarian.

Conger, J. A. 1990. The dark side of leadership. Organizational Dynamics, 19(2): 44-55.

Conger, J. A. 1998. Qualitative research as a cornerstone methodology for understanding leadership. Leadership Quarterly, 9: 107-121.

Conger, J. A. 2000. Effective change begins at the top. In M. Beer \& N. Nohria (Eds.), Breaking the code of change: 99-112. Boston: Harvard Business School Press.

Crisp, R. 2000. Aristotle: Nicomachean ethics. Cambridge, U.K: Cambridge University Press.

Cummings, T. G., \& Worley, C. G. 2001. Organization Development and Change (7th ed.). Mason, $\mathrm{OH}$ : South-Western.

Daft, R. L., \& Weick, K. E. 1984. Toward a model of organizations as interpretation systems. Academy of Management Review, 9: 284-295.

Das, R. 2005. Hinduism. Milwaukee: World Almanac Library.

Dawson, P. 1994. Organizational change: A processual approach. London: Chapman.

Day, D. V. 2000. Leadership development: A review in context. Leadership Quarterly, 11: 581-614.
De Cremer, D., Mayer, D. M., van Dijke, M., Bardes, M., \& Schouten, B. C. 2009. When does self-sacrificial leadership motivate prosocial behavior? It depends on followers' prevention focus. Journal of Applied Psychology, 94: 887-899.

DeSilver, D. 2008. \$7 billion gives shaky WaMu firmer footing for now. http://seattletimes.nwsource.com/ html/businesstechnology/2004336243_wamu09.html. Accessed April 18, 2011.

Detert, J. R., \& Burris, E. R. 2007. Leadership behavior and employee voice: Is the door really open? Academy of Management Journal, 50: 869-884.

Dickson, M. W., Resick, C. J., \& Hanges, P. J. 2006. When organizational climate is unambiguous, it is also strong. Journal of Applied Psychology, 91: 351-364.

Dotlich, D., \& Cairo, P. 2003. Why CEO's fail. San Francisco: Jossey-Bass.

Drath, W. 2001. The deep blue sea: Rethinking the source of leadership. San Francisco: Jossey-Bass and Center for Creative Leadership.

Dunphy, D. 2000. Embracing paradox: Top-down versus participative management of organizational change, a commentary on Conger and Bennis. In M. Beer \& N. Nohria (Eds.), Breaking the code of change: 99112. Boston: Harvard Business School Press.

Dutton, J. E., \& Heaphy, E. 2003. The power of high quality connections. In K. Cameron, J. E. Dutton \& R. E. Quinn (Eds.), Positive organizational scholarship: 263-278. San Francisco: Berrett-Koehler.

Dutton, J. E., Roberts, L. M., \& Bednar, J. 2010. Pathways for positive identity construction at work: Four types of positive identity and the building of social resources. Academy of Management Review, 35: 285-293.

Dvir, T., Eden, D., Avolio, B. J., \& Shamir, B. 2002. Impact of transformational leadership on follower development and performance: A field experiment. Academy of Management Journal, 45: 735-744.

Dweck, C. S. 1991. Self-theories: Their role in motivation, personality and development. Philadelphia: Psychology Press.

Dweck, C. S., Chiu, C., \& Hong, Y. 1995. Implicit theories and their role in judgments and reactions: A word from two perspectives. Psychological Inquiry, 6: 267-285.

Eagly, A. H. 2007. Female leadership advantage and disadvantage: Resolving the contradictions. Psychology of Women Quarterly, 31: 1-12.

Eagly, A. H., \& Karau, S. J. 2002. Role congruity theory of prejudice toward female leaders. Psychological Review, 109: 573-598.

Edmondson, A. C. 1999. Psychological safety and learning behavior in work teams. Administrative Science Quarterly, 44: 350-383. 
Edmondson, A. C. 2004. Psychological safety, trust, and learning in organizations: A group-level lens. In R. M. Kramer \& K. S. Cook (Eds.), Trust and distrust in organizations: Dilemmas and approaches: 239272. New York: Russell Sage Foundation.

Edmondson, A. C., \& McManus, S. E. 2007. Methodological fit in management field research. Academy of Management Review, 32: 1155-1179.

Ehrhart, M. G. 2004. Leadership and procedural justice climate as antecedents of unit-level organizational citizenship behavior. Personnel Psychology, 57: 6194.

Eisenhardt, K. M. 1989. Building theories from case study research. Academy of Management Review, 14: $532-550$.

Eisenhardt, K., \& Graebner, M. 2007. Theory building from cases: Opportunities and challenges. Academy of Management Journal, 50: 25-32.

Engineer, A. 2003. On developing theology of peace in Islam. New Delhi: Sterling.

Exline, J., \& Geyer, A. 2004. Perceptions of humility: A preliminary study. Self and Identity, 3: 95-115.

Fiedler, F. E. 1958. Leader attitudes and group effectiveness. Urbana: University of Illinois Press.

Fiske, S. T. 1993. Controlling other people: The impact of power on stereotyping. American Psychologist, 48: 621-628.

Fiske, S. T., \& Taylor, S. E. 1984. Social cognition. Reading, MA: Addison-Wesley.

Fleishman, E. A. 1953. Leadership climate and human relations training. Personnel Psychology, 6: 205222.

Gabriel, Y. 1997. Meeting god: When organizational members come face to face with the supreme leader. Human Relations, 50: 315-352.

Gaughan, A. C. 2001. Effective leadership behaviour: Leading "the third way" from a primary care group perspective-A study of leadership constructs elicited from members of primary care group management boards. Journal of Management in Medicine, 15: 67-94.

Gephart, R. P. 1984. Making sense of organizationally based environmental disasters. Journal of Management, 10: 205-225.

Glaser, B. G., \& Strauss, A. 1967. Discovery of grounded theory: Strategies for qualitative research. Mill Valley, CA: Sociology Press.

Goodman, P. S., \& Morgenson, G. 2008. Saying yes: WaMu built empire on shaky loans. http://www. nytimes.com/2008/12/28/business/28wamu.html? pagewanted=all. Acessed April 182011.

Graen, G. B., \& Uhl-Bien, M. 1995. Relationship-based approach to leadership: Development of leadermember exchange (LMX) theory of leadership over 25 years: Applying a multi-level multidomain perspective. Leadership Quarterly, 6: 219-247.

Graham, J. W. 1991. Servant-leadership in organizations: Inspirational and moral. Leadership Quarterly, 2: 105-119.

Grandey, A. A., Fiske, G. M., Mattila, A. S., Jansen, K. J., \& Sideman, L. A. 2005. Is "service with a smile" enough? Authenticity of positive displays during service encounters. Organizational Behavior and Human Decision Processes, 96: 38-55.

Grant, A. M., Parker, S. K., \& Collins, C. G. 2009. Getting credit for proactive behavior: Supervisor reactions depend on what you value and how you feel. Personnel Psychology, 62: 31-55.

Greenleaf, R. K., \& Spears, L. C. 2002. Servant leadership: A journey into the nature of legitimate power and greatness. Mahwah, NJ: Paulist Press.

Grenberg, J. M. 2005. Kant and the ethics of humility: A story of dependence, corruption and virtue. Cambridge, U.K.: Cambridge University Press.

Hambrick, D. C., \& Mason, P. A. 1984. Upper echelons: The organization as a reflection of its top managers. Academy of Management Review, 9: 193-206.

Hannah, S. T., Uhl-Bien, M., Avolio, B. J., \& Cavarretta, F. L. 2009. A framework for examining leadership in extreme contexts. Leadership Quarterly, 20: 897919.

Hareli, S., \& Rafaeli, A. 2008. Emotion cycles: On the social influence of emotion in organizations. In $\mathrm{A}$. Brief \& B. M. Staw (Eds.), Research in organizational behavior, vol. 28: 35-59. Greenwich, CT: JAI.

Hayes, J. 2002. The theory and practice of change management. Basingstoke, UK: Palgrave.

Heaphy, E. D., \& Dutton, J. E. 2008. Positive social interactions and the human body at work: Linking organizations and physiology. Academy of Management Review, 33: 137-162.

Hekman, D., Aquino, K., Owens, B., Mitchell, T., Schilpzand, P., \& Leavitt, K. 2010. An examination of whether and how racial and gender biases influence customer satisfaction ratings. Academy of Management Journal, 53: 238-264.

Hersey, P. 1985. The situational leader. New York: Warner.

Higgins, E. T. 1989. Self-discrepancy theory: What patterns of self-beliefs cause people to suffer? Advances in Experimental Social Psychology, 22: 93-136.

Hofstede, G., \& Hofstede, G. J. 2005. Cultures and organizations: Software of the mind (2nd ed.). New York: McGraw-Hill. 
House, R. J. 1996. Path-goal theory of leadership: Lessons, legacy, and a reformulated theory. Leadership Quarterly, 7: 323-352.

House, R. J., \& Baetz, M. L. 1979. Leadership: Some empirical generalizations and new research directions. In B. Staw (Ed.), Research in organizational behavior, vol. 1: 341-423. Greenwich, CT: JAI.

Hughes, L. W. 2010. Leadership under pressure: Tactics from the front line. Leadership and Organization Development Journal, 31: 187-188.

Hume, D. 1994. Political writings. Indianapolis: Hackett.

Isabella, L. 1990. Evolving interpretations as a change unfolds: How managers construe key organizational events. Academy of Management Journal, 33: $7-41$.

Jenner, R. A. 1998. Dissipative enterprises, chaos, and the principles of lean organizations. Omega: International Journal of Management Science, 26: 397407.

Judge, T. A., Bono, J. E., Ilies, R., \& Gerhardt, M. W. 2002. Personality and leadership: A qualitative and quantitative review. Journal of Applied Psychology, 87: 765-780.

Kahn, W. A. 1990. Psychological conditions of personal engagement and disengagement at work. Academy of Management Journal, 33: 692-724.

Kark, R., Shamir, B., \& Chen, G. 2003. Two faces of transformational leadership: Empowerment and dependency. Journal of Applied Psychology, 88: 246255.

Kerfoot, K. 1998. The strategic use of humility. Nursing Economics, 16: 238-239.

Kerr, S. 1977. Substitutes for leadership: Some implications for organizational design. Organization and Administrative Sciences, 8: 135-146.

Kim, S. 2002. Participative management and job satisfaction: Lessons for management leadership. Public Administration Review, 62: 231-241.

Kipnis, D. 1972. Does power corrupt? Journal of Personality and Social Psychology, 24: 33-41.

Klein, K. J., Ziegert, J. C., Knight, A. P., \& Xiao, Y. 2006. Dynamic delegation: Shared, hierarchical and deindividualized leadership in extreme action teams. Administrative Science Quarterly, 50: 590621.

Knottnerus, J. D., Ulsperger, J. S., Cummins, S., \& Osteen, E. 2006. Exposing Enron, Media representations of ritualized deviance in corporate culture. Crime, $\mathbf{M e}-$ dia, Culture: An International Journal, 2(2): 177195.
Kouzes, J. M., \& Posner, B. Z. 1997. Leadership practices inventory: A self-assessment and analysis (Expanded Ed.). San Francisco: Jossey-Bass.

Kram, K. E. 1985. Mentoring at work: Developmental relationships in organizational life. Glenview, IL: Scott, Foresman.

Kreiner, G. E., Hollensbe, E. C., \& Sheep, M. L. 2006. Where is the "me" among the "we"? Identity work and the search for optimal balance. Academy of Management Journal, 49: 1031-1057.

Landis, R. J., \& Koch, G. G. 1977. The measurement of observer agreement for categorical data. Biometrics, 33: $159-174$.

Lauer, C. S. 2002. The basic recipe for a leader. Modern Healthcare, 32: 33.

Leana, C. R. 1986. Predictors and consequences of delegation. Academy of Management Journal, 29: 754774 .

Lee, T. W. 1999. Using qualitative methods in organizational research. Thousand Oaks, CA: Sage.

Lichtenstein, B. B., Uhl-Bien, M., Marion, R., Seers, A., Orton, J. D., \& Schreiber, C. 2006. Complexity leadership theory: An interactive process on leading in complex adaptive systems. In J. K. Hazy, J. A. Goldstein \& B. B. Lichtenstein (Eds.), Complex systems leadership theory: New perspectives from complexity science on social and organizational effectiveness: 129-141. Mansfield, MA: ISCE.

Lord, R. G., \& Brown, D. J. 2001. Leadership, value, and subordinate self-concepts. Leadership Quarterly, 12: 133-152.

Lord, R., \& Maher, K. J. 1991. Leadership and information processing: Linking perceptions to performance. Boston: Unwin-Hyman.

Lovaglia, M. J., \& Houser, J. A. 1996. Emotional reactions to status in groups. American Sociological Review, 61: 867-883.

Marinoff, L. 2007. The middle way: Finding happiness in a world of extremes. New York: Sterling.

Maslach, C., \& Leiter, M. P. 1997. The truth about burnout: How organizations cause personal stress and what to do about it. San Francisco: Jossey-Bass.

Matteson, J. A., \& Irving, J. A. 2006. Servant versus selfsacrificial leadership: A behavioral comparison of two follower-oriented leadership theories. International Journal of Leadership Studies, 2: 36-51.

Mauno, S., Kinnunen, U., \& Ruokolainen, M. 2007. Job demands and resources as antecedents of work engagement: A longitudinal study. Journal of Vocational Behavior, 70: 149-171.

McConnell, M. W. 1996. The importance of humility in judicial review: A comment on Ronald Dworkin's 
"moral reading" of the constitution. Fordham Law Review, 65: 1269-1293.

McCullough, M. E. 2000. Forgiveness as a human strength: Theory, measurement, and links to wellbeing. Journal of Social and Clinical Psychology, 19: 43-55.

Meyer, E. C. 1997. Leadership: A return to basics. Military Review, 77: 58-61.

Miles, M. B., \& Huberman, A. M. 1994. Qualitative data analysis: An expanded source book. Thousand Oaks, CA: Sage.

Mitchell, T. R., \& James, L. R. 2001. Building better theory: Time and the specification of when things happen. Academy of Management Review, 26: 530547.

Mitchell, T., \& Thompson, L. 1994. A theory of temporal adjustments of the evaluation of events: Rosy prospection \& rosy retrospection. In C. Stubbart, J. Porac, \& J. Meindl (Eds.), Advances in managerial cognition and organizational information processing: 85-114. Greenwich, CT: JAI.

Morris, J. A., Brotheridge, C. M., \& Urbanski, J. C. 2005. Bringing humility to leadership: Antecedents and consequences of leader humility. Human Relations, 58: $1323-1350$.

Murrell, K. L. 1997. Emergent theories of leadership for the next century: Towards relational concepts. Organization Development Journal, 15(3): 35-42.

Nava, M. 2008. The servant of all: Humility, humanity, and judicial diversity. Golden Gate University Law Review, 38: 175-194.

Nielsen, R., Marrone, J., \& Slay, H. 2010. A new look at humility: Exploring the humility concept and its role in socialized charismatic leadership. Journal of Leadership and Organizational Studies, 17: 33-43.

Obama, B. 2008. Renewing American leadership. Foreign Affairs, 86: 2-16.

Overbeck, J. R., Neale, M. A., \& Govan, C. 2010. I feel, therefore you act: Intrapersonal and interpersonal effects of emotion on negotiation as a function of social power. Organizational Behavior and Human Decision Processes, 112: 126-139.

Owens, B. P. 2008. Humility in organizations: Establishing construct, nomological, and predictive validity. Academy of Management best Paper proceedings.

Owens, B. P., Johnson, M. J., \& Mitchell, T. R. 2012. Humility in organizations: Implications for performance, teams, and leadership. Organization Science: In press.

Owens, B. P., Rowatt, W. C., \& Wilkins, A. L. 2011. Exploring the relevance and implications of humility in organizations. In K. S. Cameron \& G. S. Spreitzer (Eds.), Handbook of positive organizational scholarship: 260-272. Oxford, U.K.: Oxford University Press.

Park, N., \& Peterson, C. 2003. Virtues and organizations. In K. S. Cameron, J. E. Dutton, \& R. E. Quinn (Eds.), Positive organizational scholarship: Foundations of a new discipline: 33-47. San Francisco: BerrettKoehler.

Parker, S. K., Williams, H. M., \& Turner, N. 2006. Modeling the antecedents of proactive behavior at work. Journal of Applied Psychology, 91: 636-652.

Payne, G., \& Williams, M. 2005. Generalization in qualitative research. Sociology, 39: 295-314.

Pearce, C. L. 2004. The future of leadership: Combining vertical and shared leadership to transform knowledge work. Academy of Management Executive, 18(1): 47-59.

Pearce, C. L., \& Conger, J. A. 2003. Shared leadership: Reframing the hows and whys of leadership. Thousand Oaks, CA: Sage.

Poirier, J. 2007. Top five US subprime lenders asked to testify-Dodd. In Reuters. Available at: http://www. reuters.com/article/idUSN1930675220070319. Accessed on March 17, 2008.

Quinn, R. E., \& Rohrbaugh, J. 1983. A spatial model of effectiveness criteria: Towards a competing values approach to organizational analysis. Management Science, 29: 363-377.

Quinn, R. W., \& Worline, M. C. 2008. Enabling courageous collective action: Conversations from United Airlines flight 93. Organization Science, 19: 497516.

Rafferty, A. E., \& Griffin, M. A. 2006. Perceptions of organizational change: A stress and coping perspective. Journal of Applied Psychology, 91: 11541162.

Ragins, B. R., \& Winkel, D. E. 2008. Gender, emotion and power in work relationships. In Academy of Management best Paper proceedings.

Rhodewalt, F., \& Morf, C. C. 1998. On self-aggrandizement and anger: A temporal analysis of narcissism and affective reactions to success and failure. Journal of Personality and Social Psychology, 74: 672685.

Rosenthal, S. A., \& Pittinsky, T. L. 2006. Narcissistic leadership. Leadership Quarterly, 17: 617-633.

Rosette, A. S., Leonardelli, G. J., \& Phillips, K. W. 2008. The white standard: Racial bias in leader categorization. Journal of Applied Psychology, 93: 758-777.

Rost, J. C. 1991. Leadership for the twenty-first century. London: Praeger.

Rost, J. C. 1995. Leadership: A discussion about ethics. Business Ethics Quarterly, 5: 129-142. 
Rousseau, D. 2007. A sticky, leveraging, and scalable strategy for high-quality connections between organizational practice and science. Academy of Management Journal, 50: 1037-1042.

Rudman, L. A., \& Glick, P. 1999. Feminized management and backlash toward agentic women: The hidden costs to women of a kinder, gentler image of middle managers. Journal of Personality and Social Psychology, 77: 1004-1010.

Ruggero, E. 2009. Gary Cooper style. http:/views. washingtonpost.com/leadership/panelists/2009/11/ gary-cooper-style.html. Accessed March 19, 2010.

Sayles, L. R. 1993. The working leader: The triumph of high performance over conventional management principles. New York: Free Press.

Scharffs, B. 1998. The role of humility in exercising practical wisdom. University of California, Davis, Law Review, 32: 127-199.

Schaufeli, W. B., \& Bakker, A. B. 2004. Job demands, job resources and their relationship with burnout and engagement: A multi-sample study. Journal of Organizational Behavior, 25: 293-315.

Schimmel, S. 1992. The seven deadly sins: Jewish, Christian, and classical reflections on human nature. New York: Free Press.

Schutz, A. 1972. The phenomenology of the social world. London: Heinemenn Educational Books.

Seibert, S., Kraimer, M. L., \& Crant, J. M. 2001. What do proactive people do? A longitudinal model linking proactive personality and career success. Personnel Psychology, 54: 845-874.

Senge, P. M. 1990. The fifth discipline. London: Century Business.

Sluss, D. M., \& Ashforth, B. E. 2007. Relational identity and identification: Defining ourselves through work relationships. Academy of Management Review, 32: 9-32.

Snelling, J. 1998. The Buddhist handbook: A complete guild to Buddhist schools, teaching, practice, and history. Rochester, VT: Inner Traditions International.

Somech, A. 2003. Relationships of participative leadership with relational demography variables: A multilevel perspective. Journal of Organizational Behavior, 24: 1003-1018.

Spears, L. C. 1998. Insights on leadership: Service, stewardship, spirit and servant leadership. New York: Wiley.

Spreitzer, G., \& Mishra, A. 2002. To stay or go: Voluntary survivor turnover following an organizational downsizing. Journal of Organizational Behavior, 23: 707-729.
Staw, B. 1981. The escalation of commitment to a course of action. Academy of Management Review, 6: $577-587$.

Staw, B. M., Sandelands, L. E., \& Dutton, J. E. 1981. Threat-rigidity effects on organizational behavior. Administrative Science Quarterly, 26: 501-524.

Suchman, M. 1995. Managing legitimacy: Strategic and institutional approaches. Academy of Management Review, 20: 571-611.

Suddaby, R. 2006. What grounded theory is not. Academy of Management Journal, 49: 633-642.

Swift, T. A., \& West, M. A. 1998. Reflexivity and group processes: Research and practice. Sheffield, U.K.: University of Sheffield.

Tangney, I. P. 2000. Humility: Theoretical perspectives, empirical findings and directions for future research. Journal of Social and Clinical Psychology, 19: 7082.

Templeton, J. 1997. Worldwide laws of life. Philadelphia: Templeton Foundation.

Tiedens, L. Z., Ellsworth, P. C., \& Mesquita, B. 2000. Stereotypes about sentiments and status: Emotional expectations for high- and low-status group members. Personality and Social Psychology Bulletin, 26: $560-574$.

Trejos, N. 2007. Existing-home sales fall steeply. http:// www.washingtonpost.com/wpdyn/content/article/ 2007/04/24/AR2007042400627.html. Accessed March 17,2008

Uhl-Bien, M. 2006. Relational leadership theory: Exploring the social processes of leadership and organizing. Leadership Quarterly, 17: 654-676.

Vashdi, D. R., Bamberger, P. A., Erez, M., \& Weiss-Meilik, A. 2007. Briefing-debriefing: Using a reflexive organizational learning model from the military to enhance the performance of surgical teams. Human Resource Management, 46: 115-142.

Vera, D., \& Rodriguez-Lopez, A. 2004. Humility as a source of competitive advantage. Organizational Dynamics, 33: 393-408.

Wagner, D. G., \& Berger, J. 1997. Gender and interpersonal task behaviors: Status expectation accounts. Sociological Perspectives, 40: 1-32.

Walsh, J. P., Henderson, C. M., \& Deighton, J. 1988. Negotiated belief structures and decision performance: An empirical investigation. Organizational Behavior and Human Decision Processes, 42: $194-216$.

Walumbwa, F. O., Avolio, B. J., Gardner, W. L., Wernsing, T. S., \& Peterson, S. J. 2008. Authentic leadership: Development and validation of a theorybased measure. Journal of Management, 34: 89126. 
Weick, K. E. 1993. The collapse of sensemaking in organizations: The Mann Gulch disaster. Administrative Science Quarterly, 38: 628-652.

Weick, K. E. 2001. Leadership as the legitimization of doubt. In W. Bennis, G. M. Spreitzer, \& T. G. Cummings (Eds.), The future of leadership: Today's top leadership thinkers speak to tomorrow's leaders: 91-102. San Francisco: Jossey-Bass.
Wilson, J. 2009. Buddhism of the heart: Reflections on Shin Buddhism and inner togetherness. Somerville, MA: Wisdom Publications.

Yukl, G. 1999. An evaluation of conceptual weaknesses in transformational and charismatic leadership theories. Leadership Quarterly, 10: 285-305.

Yukl, G. 2010. Leadership in organizations. Upper Saddle River, NJ: Pearson.
Bradley P. Owens (bpowens@buffalo.edu) is an assistant professor in the School of Management at the State University of New York, Buffalo. He holds a Ph.D. in management from the University of Washington. His current research focuses on positive organizational scholarship as it relates to leadership, identity, team processes, diversity, and work/life balance.
David R. Hekman (hekman@uwm.edu) is an assistant professor of management at the Leeds School of Business, University of Colorado at Boulder. He earned his Ph.D. in management from the University of Washington. He is interested in improving organizational health by minimizing organizational problems such as ineffective leadership, weak employee attachment, and persistent workplace inequality. 